DOI:10.2151/jmsj.2010-303

\title{
Convective Boundary Layer above a Subtropical Island Observed by C-band Radar and Interpretation using a Cloud Resolving Model
}

\author{
Haruya MINDA and Fumie A. FURUZAWA \\ Hydrospheric Atmospheric Research Center, Nagoya University, Nagoya, Japan \\ Shinsuke SATOH \\ National Institute of Information and Communications Technology, Koganei, Japan \\ Kenji NAKAMURA \\ Hydrospheric Atmospheric Research Center, Nagoya University, Nagoya, Japan \\ (Manuscript received 26 November 2007, in final form 18 January 2010)
}

\begin{abstract}
This paper describes the evolution of the convective boundary layer (CBL) and the initiation of clouds above Okinawa Island, Japan, during summer conditions with weak synoptic forcing and clear skies. An intensive observational campaign using a C-band precipitation radar (COBRA) and radio sonde was conducted on the island in early July 2005. These soundings exhibited diurnal variations in the potential temperature and water vapor in the atmospheric boundary layer. COBRA observed clear-air radar echoes (CAEs) within a 10-km radar range, and the CAE height showed a diurnal variation as well. To investigate the nature of the CAEs and to describe the dynamics of the CBL structure, a high-resolution cloud resolving model simulation was performed for two cases; a cumulus street and a distinct roll cloud. Flat and undulated surface models were used to understand the orographic effects on cloud initiation. On the basis of these investigations, we found strong consistency within the simulated radar reflectivity and observed CAE distributions. COBRA regularly observes turbulent moisture motions at cloud edges and occasionally detects moisture convergence in the CBL. The model CBL evolutions coincide well with the diurnal variations of CAE height, thereby showing that the island presents a good case for studying CBL evolution and that COBRA is useful to find the CBL depth here. The model results show that the warmed island induces horizontal convective rolls and a convergent zone above the island. A merging of the thermals, the rolls, and the sea-breeze reinforces the upward energy transfer, which generates a cumulus street and a distinct roll cloud being supported by orographic uplift. Wind direction characterizes a moist CBL formation and the cloud initiations above Okinawa Island.
\end{abstract}

\section{Introduction}

Convective thermals create the convective boundary layer (CBL) and uplift moisture to the inversion layer through a buffering interaction be-

Corresponding author: Haruya Minda, Hydrospheric Atmospheric Research Center, Nagoya University, Nagoya, 464-8601, Japan.

E-mail: minda@hyarc.nagoya-u.ac.jp

(C) 2010, Meteorological Society of Japan tween the CBL and the free atmosphere. Cumulus clouds in particular are effective in the exchange of heat and moisture at the interaction layer. The surface layer of the CBL has been well documented through direct observations using flux measuring towers. Recent remote sensing techniques such as windprofiler radars (WPRs) and lidars much improve the ability to capture turbulent air motion in the upper layer of the CBL. One way to obtain a vertical $\mathrm{CBL}$ profile is by using a combination of a 
flux tower and WPR, and this method was used in past studies (e.g., Tanaka et al. 2007). To date, creation of the CBL over flat terrain has been the subject of both theoretical and observational studies. The CBL exists naturally even over relatively small islands, which easily develop shallow cumulus and occasionally a long cumulus street to the leeward. Even small islands can produce significant impacts on large-scale precipitation systems. As an extreme example, a small island might trigger a severe rainfall line over its leeward land (Adachi et al. 2004). It is therefore well worth investigating CBL structures over islands. Matthews et al. (2007) reported a long cumulus street generation to the leeward of an isolated small island, and an island effect in the atmospheric boundary layer to the leeward over a $20-\mathrm{km}$ distance. Ito (1997) reported that an island's steep coastal terrain affects the boundary layer structure over the island and that this effect is visible through Doppler sodar observation. The marine boundary layer created over the ocean is weak because of the small sensible heat flux from the sea surface. Over land, solar radiation produces intense sensible heat flux from the land surface because of the small heat capacity of land surfaces, and the heat flux creates a strong CBL. The CBL created over islands may be the result of a combination of the weak marine boundary layer and the strong land CBL. This study focuses on the CBL evolution above a subtropical island during summer conditions with weak synoptic forcing and clear skies.

We conducted an intensive observational campaign on Okinawa Island in early July of 2005. Okinawa Island is a subtropical island located in the southwestern region of Japan. The island is northeastwardly oriented, $110-\mathrm{km}$ long, 5 to $25-\mathrm{km}$ wide, and $1200 \mathrm{~km}^{2}$ in area. The National Institute of Information and Communications Technology (NICT) maintains atmospheric observation facilities on Okinawa Island, including a C-band polarimetric precipitation radar (COBRA), a UHF WPR, a radio sonde system, and other sensors. This study used the scanning radar COBRA to produce a twodimensional profile of thermal and cumulus initiation. Okinawa Island is characterized as having intense solar radiation during summer. This solar radiation warms the surface and actively induces convective thermals, thereby developing the CBL. The rising thermals transport moisture aloft and cause irregularities in moisture distribution. Fluctuations of atmospheric refractivity due to turbulence scatter microwaves, known as Bragg scattering.
Strong Bragg scattering often occurs at places of a distinct moisture variation such as thermal edges because refractivity depends strongly on moisture amount in the CBL (Tatarskii 1961). Radar detects air motion by receiving the weak signals of Bragg scattering. Particularly long-wavelength radars $(>15 \mathrm{~cm})$ capture air motions well. Precipitation radar (wavelength $\leq 15 \mathrm{~cm}$ ) occasionally detects Bragg scattering echoes in fair weather (Kropfli 1983), known as clear-air radar echoes (CAEs). Sband radars in particular often observe CAEs, and they have been used to observe wind in clear sky conditions (Crum et al. 1993). Knight and Miller (1993) investigated echoes of shallow cumulus within a $10-\mathrm{km}$ radar range, and they proposed a threshold radar reflectivity of $0 \mathrm{dBZ}$ at C-band to differentiate CAEs from hydrometer echoes. Lothon et al. (2002) demonstrated the CBL profiling capability by $\mathrm{C}$-band scanning radar over a flat and homogeneous plain, and they further depicted the vertical development of the CBL similar to that of a UHF WPR.

Neither observations by radars nor soundings alone are sufficient to fully characterize the temporal and spatial evolution of a CBL. A numerical model is also helpful for filling in meteorological quantities that are absent in observations. A highresolution numerical model is a powerful tool in describing the dynamics of CBLs. Heretofore, several researchers have studied CBL structures using numerical models, particularly over flat land in dry conditions. For example, Sullivan et al. (1998) investigated the entrainment mechanism of the inversion layer and found the structure to be in good agreement with lidar observations over flat terrain. Endo et al. (2008) investigated the characteristics of a moist CBL over humid, flat land and pointed out that moisture reinforces buoyancy forces and strongly contributes to the evolution of the CBL. The dry CBL forms rapidly in the morning because of an intense sensible heat flux, whereas the moist CBL forms slowly until the late afternoon because of lower sensible heat flux and large latent heat flux. Recent advances in computer technology allow convenient, high-resolution numerical simulations over complex terrain. Researchers have demonstrated that simulations with a sub-kilometer horizontal spacing can capture useful meteorological features over complex terrains such as steep valleys (Zhong and Fast 2003; Chow et al. 2006). Tian et al. (2003) investigated orographic effects on convective rolls using a sub-kilometer resolution model 
for cases in which an S-band radar clearly observed a CAE that was formed by cellular convective rolls over a hilly plain in summer. They showed that orographical uplifts and corresponding downdrafts have a significant impact on convective activity and demonstrated that high mountains disturb circulations rather than initiating convection.

This paper investigates moist CBL structures and cloud initiations above Okinawa Island characterized by a very moist surface layer and intense solar radiation, using COBRA and a high-resolution cloud resolving model through two case studies: a distinct roll cloud generated around noon on 8 July and a cumulus street in the afternoon on July 7, 2005.

\section{Observations}

We conducted an intensive observational campaign exploring the formation of the $\mathrm{CBL}$ and the initiation of shallow cumulus convection using $\mathrm{CO}$ BRA and other instruments on Okinawa Island from July 1 to July 9, 2005. Okinawa Island is located in the southwestern subtropical region in Japan (Fig. 1). The island is a northeasterly oriented long and narrow island, $110-\mathrm{km}$ long and 5 to $25-\mathrm{km}$ wide. Mountain ranges with elevation 240 $500 \mathrm{~m}$ dominate the northern part, and the south is an undulating terrain with elevation below $120 \mathrm{~m}$ and is urbanized. Figure 2 illustrates the observation area and the terrain shape. COBRA is located on the mountain in the middle of the island

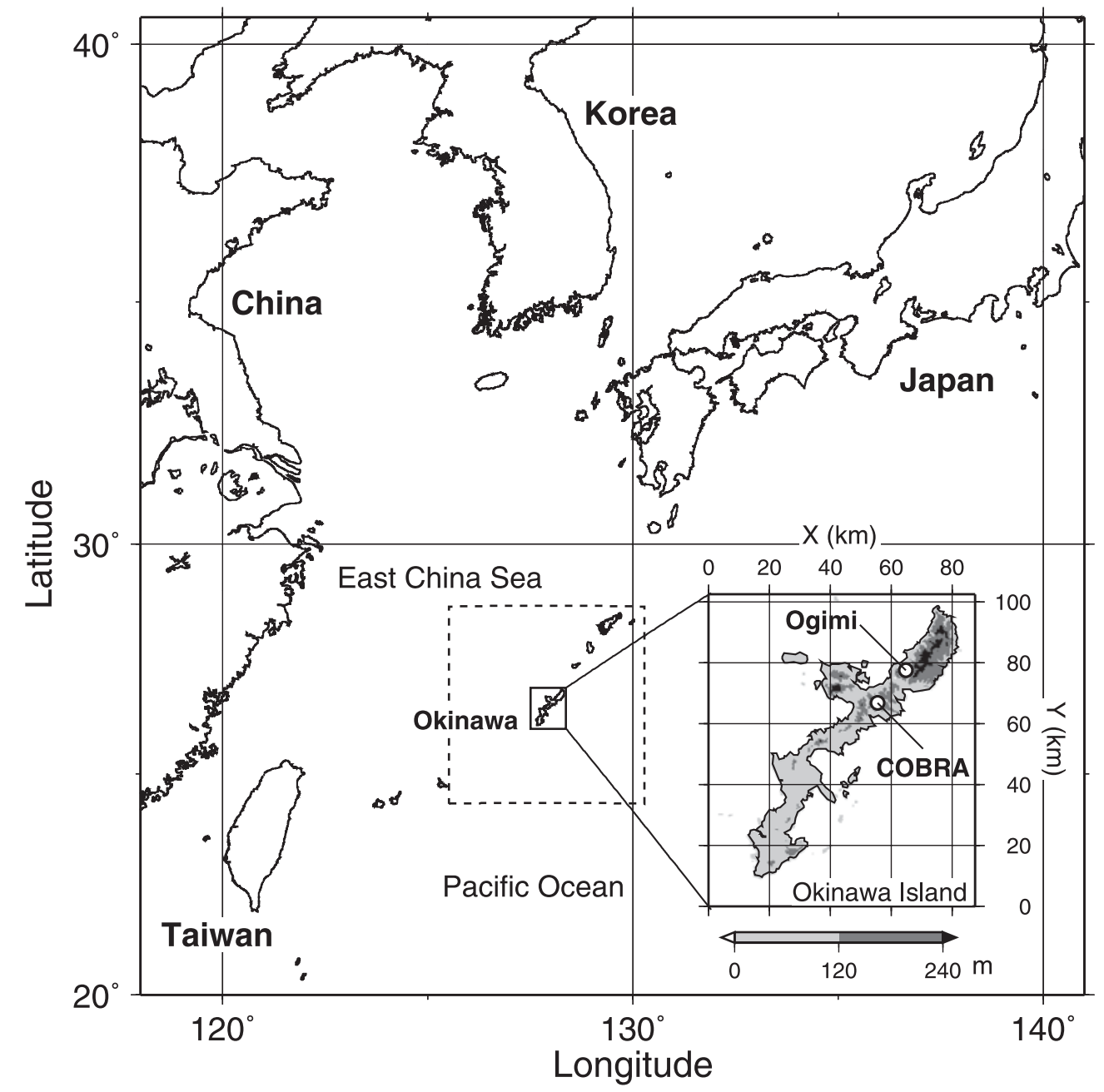

Fig. 1. Locations of Okinawa Island and the numerical model domains; the close-up map displays the finegrid model domain; the dashed box denotes the coarse-grid model domain. 


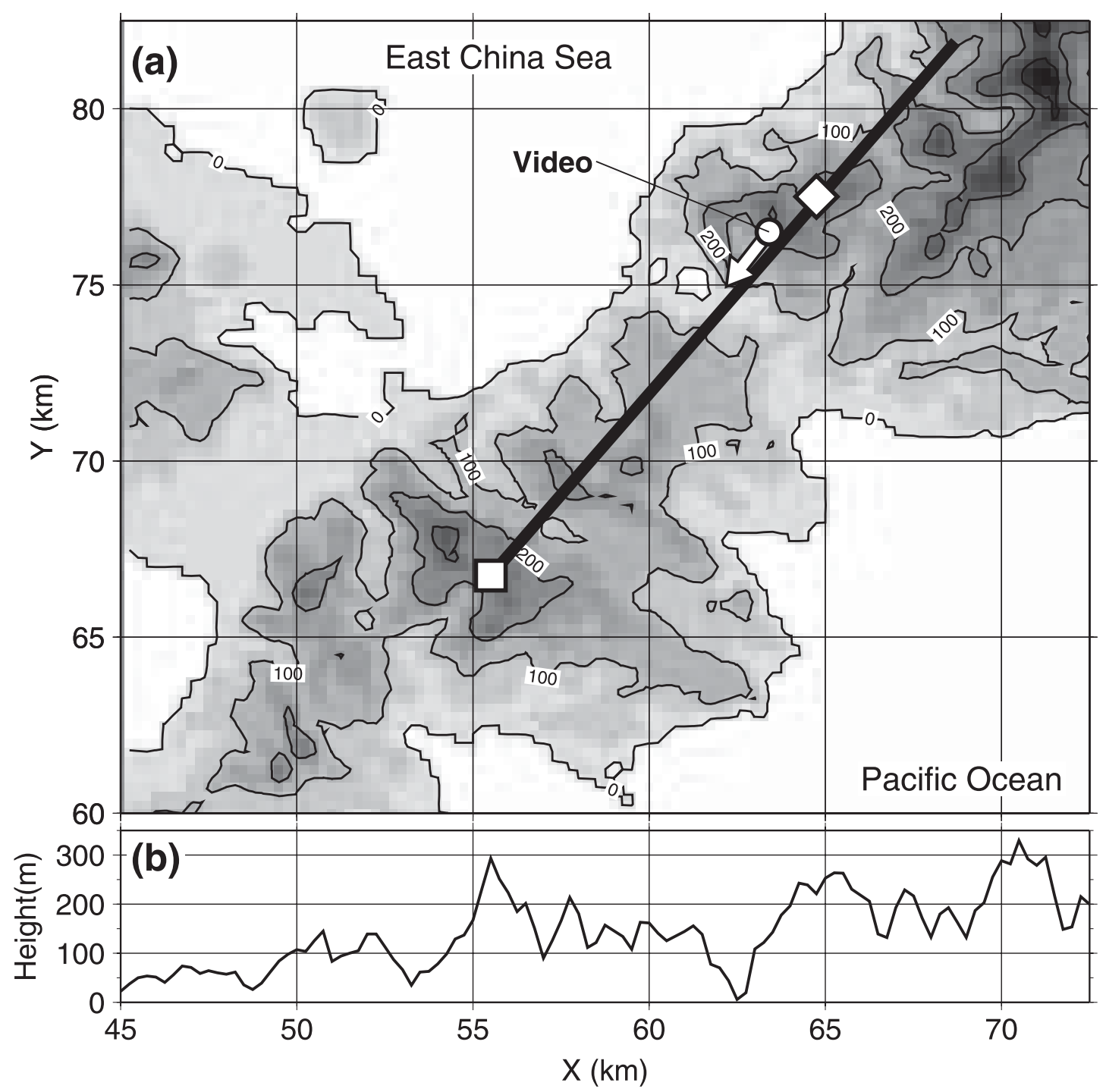

Fig. 2. (a) Instrument alignment and COBRA RHI; square and diamond denote COBRA and Ogimi sites, respectively; the circle denotes the video camera, and the arrow shows the camera view angle; the contours show the elevation every $100 \mathrm{~m}$; the solid line shows the RHI. (b) Topography along the RHI.

(26.59 N, 128.06 E, $360 \mathrm{~m}$ elevation), which allows observations using horizontal, vertical, diagonal, and circular polarized microwaves (Nakagawa et al. 2001). Another NICT observation facility is located at Ogimi $(26.68 \mathrm{~N}, 128.16 \mathrm{E}, 225 \mathrm{~m}$ elevation) in a steep mountain area in the northern part of the island. This facility is equipped with a $400 \mathrm{MHz}$ vertical pointing WPR, a radio sonde system and several other instruments. This study focused on the area between COBRA and Ogimi sites, because COBRA often observes CAEs here during the warm season. In the observations con- ducted, COBRA repeatedly acquired a range height indicator (RHI) to capture shallow cumuli developments with a high temporal resolution of $30 \mathrm{~s}$ and range resolution of $75 \mathrm{~m}$. The RHI was directed toward the Ogimi site for a comparison analysis with WPR (Fig. 2). CAEs observed by COBRA above the Ogimi site, however, showed very weak signals and suffered significantly from ground clutter. Because of this, comparison analysis between simultaneously observed COBRA and WPR signatures was not performed.

Table 1 describes the major COBRA specifica- 
Table 1. Major COBRA specification and the operational settings.

\begin{tabular}{lll}
\hline & $\begin{array}{c}\text { Range Height } \\
\text { Indicator }\end{array}$ & $\begin{array}{c}\text { Plane Position } \\
\text { Indicator }\end{array}$ \\
\hline $\begin{array}{l}\text { Frequency } \\
\text { Transmitted power } \\
\quad \text { (peak) }\end{array}$ & $\begin{array}{l}5340 \mathrm{MHz} \\
\text { System noise level }\end{array}$ & $-110 \mathrm{~dB}$ \\
Sensitivity at 10-km & $>-3 \mathrm{dBZ}$ & \\
$\quad$ range & & \\
Antenna type & $4.5 \mathrm{~m} \phi$ parabola \\
Antenna gain & $45 \mathrm{dBi}$ & \\
Beam width & $0.91 \mathrm{deg}$ & $2 \mathrm{rpm}$ \\
Antenna sweep speed & $0.5 \mathrm{rpm}$ & $0.9 \mathrm{deg}$ \\
Angular resolution & $0.4 \mathrm{deg}$ & $75 \mathrm{~m} * *$ \\
Range resolution & $75 \mathrm{~m}$ & $40 \mathrm{~km} * *$ \\
Maximum range & $20 \mathrm{~km}$ & $1.4^{* *}, 7,8 \mathrm{deg}$ \\
Elevation angles & - & - \\
Azimuth angle & $41.2 \mathrm{deg}$ &
\end{tabular}

* The minimum received power is assumed $-100 \mathrm{dBm}$.

** The range resolution was $300 \mathrm{~m}$ within the range of $200 \mathrm{~km}$ at $1.4^{\circ}$ elevation angle.

tions and operational settings. The observation sequence of COBRA consisted of three plane position indicator (PPI) scans at $1.4^{\circ}, 7^{\circ}$, and $8^{\circ}$ elevation angles (ELs) and 14 scans of the RHI at the 41.2 degree azimuth angle (AZ) every $10 \mathrm{~min}$. The PPIs at $7^{\circ}$ and $8^{\circ}$ ELs acquired horizontal CAE distributions around the CBL top layer at the height of $1-$ $1.5 \mathrm{~km}$ in the range of $7-10 \mathrm{~km}$. The PPI at $1.4^{\circ}$ EL covered a $200-\mathrm{km}$ range with $300-\mathrm{m}$ resolution to survey precipitation for switching to a rainfall observation sequence. Radiosondes were released from the Ogimi site every two hours during the day $(0800,1000,1200,1400$, and 1600 JST $)$ and every three hours at night $(1800,2100,0000,0300$, 0600 JST). As an additional observation, a video camera captured images along the RHI to supplement information on the nature of the dominant echoes.

During the observation, southwesterly winds and clear skies continued over the island because of the northwestern edge of the Pacific high-pressure system. Figure 3 shows a time-height cross-sections of sounding parameters in the second half of the observation period, including potential temperature, mixing ratio of water vapor, and wind direction and speed. The potential temperature and the water vapor show diurnal variations in the surface layer. The water vapor increased during the period from the afternoon on July 7 to the morning on July 9, but the sonde observed a dry surface layer at 1330 JST on July 8 . Winds at the height of $0.5-1.2 \mathrm{~km}$ blew steadily from the southwest $\left(210^{\circ}-230^{\circ}\right)$ along the RHI line $\left(41^{\circ}\right)$, which simplified the tracking of CAEs on the RHI. Figure 4a shows a time series of the vertical windshear (velocity difference between heights of $0.5 \mathrm{~km}$ and $2 \mathrm{~km}$ ). The windshear was about $6 \mathrm{~m} \mathrm{~s}^{-1}$ from July 6 to July 8 and about $4 \mathrm{~m} \mathrm{~s}^{-1}$ in the other periods. Figure $4 \mathrm{~b}$ shows a time series of convective available potential energy (CAPE) and convective inhibition (CIN), where CAPE and CIN are calculated by lifting an air parcel at a height of $0.3 \mathrm{~km}(75 \mathrm{~m}$ above the sounding station in the valley). The CAPE increases from the afternoon on July 7 to the morning on July 9, when the soundings observed a large amount of water vapor in the surface layer. This paper focuses on two short periods around 1300 JST on July 8 and 1500 JST on July 7. The values of CAPE in the two periods are approximately $1500 \mathrm{~J} \mathrm{~kg}^{-1}$ and CIN is nearly zero. These values suggest a similar convective instability around noon on July 8 and in the afternoon on July 7.

\section{Numerical simulation}

The Cloud Resolving Storm Simulator (CReSS) provided by Nagoya University, Japan, was used to reveal the CBL structures and irregularities of atmospheric refractivity representing CAEs (see Appendix) above Okinawa Island in the daytime (0600-1900 JST) on July 7 and July 8, 2005. CReSS is a non-hydrostatic and compressible numerical model incorporating parameterizations of sub-grid scale (SGS) eddy motions and cloud physics (Tsuboki and Sakakibara 2001). The model domain of this study (Fig. 1) covers an area of $87.5 \mathrm{~km} \times 102.5 \mathrm{~km}$, which encloses Okinawa Island with $250-\mathrm{m}$ horizontal spacing. The vertical spacing is $60 \mathrm{~m}$, evenly spaced up to a height of $4.8 \mathrm{~km}$. The topography used was from the digital elevation map (250-m resolution) distributed by the Geographical Survey Institute (GSI) in Japan (http://www.gsi.go.jp/geoinfo/dmap/dem250mindex.html). Land use was determined using Geographic Information System (GIS) data provided by the Japanese government (http://nlftp.mlit .go.jp). To establish initial conditions and lateral boundary forcing, we employed operational mesoscale analysis data, namely the grid point values (GPV) in the meso-scale model (MSM) disseminated by the Japan Meteorological Agency (Zeng 

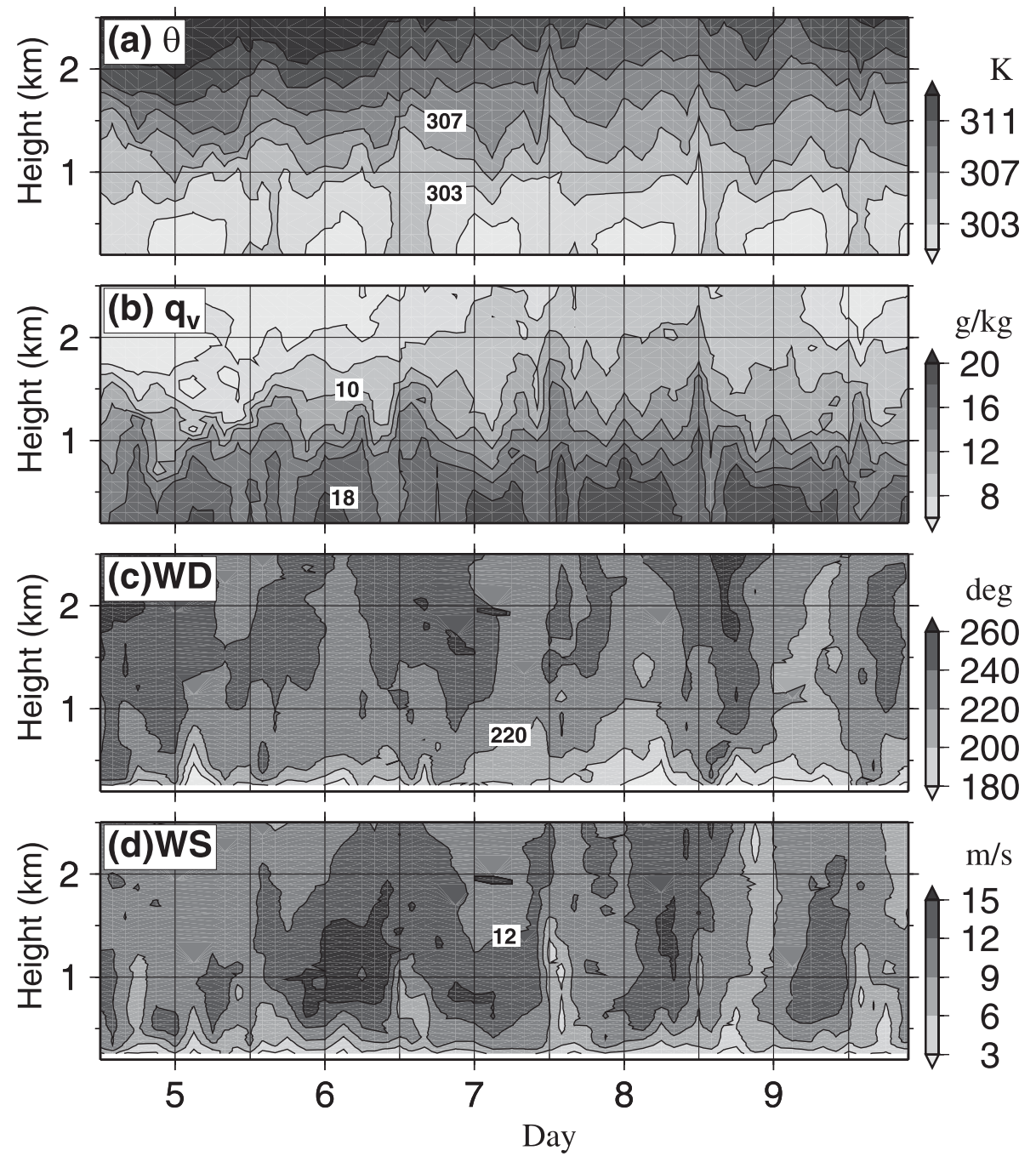

Fig. 3. Time-height cross-sections of the soundings from July 5 to July 9, 2005; (a) $\theta$, (b) $q_{v}$, (c) wind direction, and (d) wind speed; the abscissa is the date in July and the numbers correspond to 0000 JST.

et al. 2003). Because the spatial and temporal resolutions of the GPV MSM are coarser than required, we computed them using two nested domains (coarse- and fine-grid domains). The coarse-grid domain consists of $480 \mathrm{~km} \times 480 \mathrm{~km}$ with a $2-\mathrm{km}$ horizontal spacing (the dashed box in Fig. 1), and $12 \mathrm{~km}$ in the vertical with $300-\mathrm{m}$ spacing. The topography of the coarse-grid model used GTOPO30 data, the global digital elevation model distributed by the U.S. Geological Survey. The parameterization of the SGS eddy used was a 1.5-order turbulent kinetic energy (TKE) closure and the cloud physics used was a warm rain process based on a bulk method in the CReSS model. Table 2 shows the model configuration and model variables. In this study, a flat terrain model (FTM) giving zero meter elevation and the land-use information was also performed, in addition to the control model (CNTL) given the terrain shape, for investigating the orographic effect on cloud initiation.

\section{Results}

\subsection{Roll convection on July 8, 2005}

On 8 July, a distinct roll cloud appeared along the island and COBRA observed a CAE band around the COBRA RHI line around 1300 JST. Figure 5a shows cloud pictures recorded by the video camera, which reveal a roll cloud forming along 
(a) Windshear

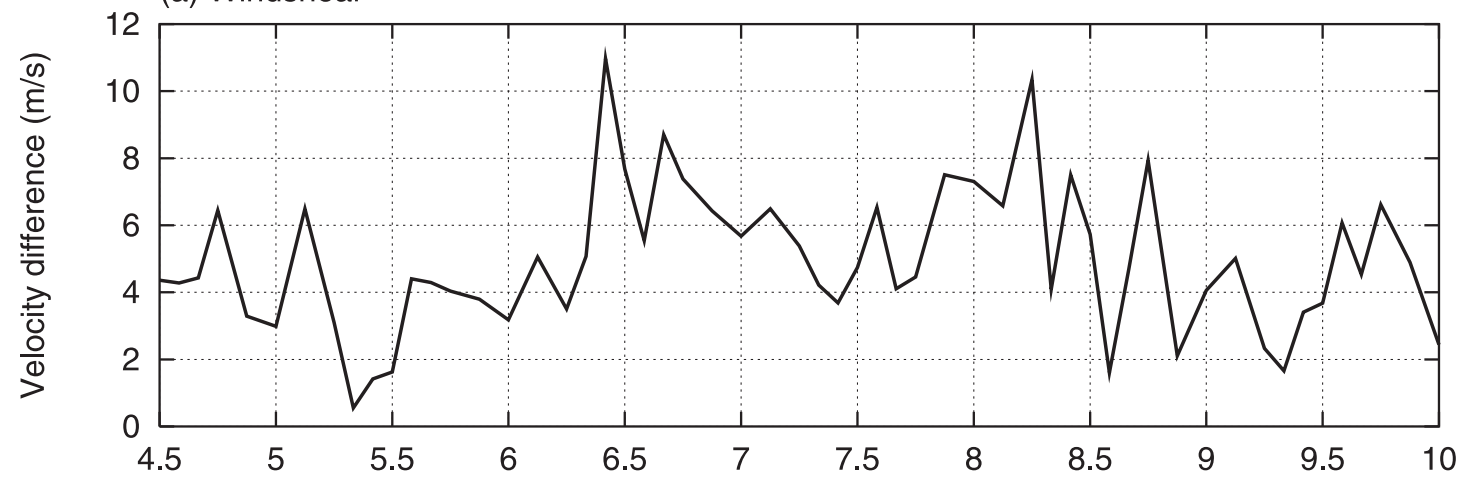

(b) CAPE and CIN

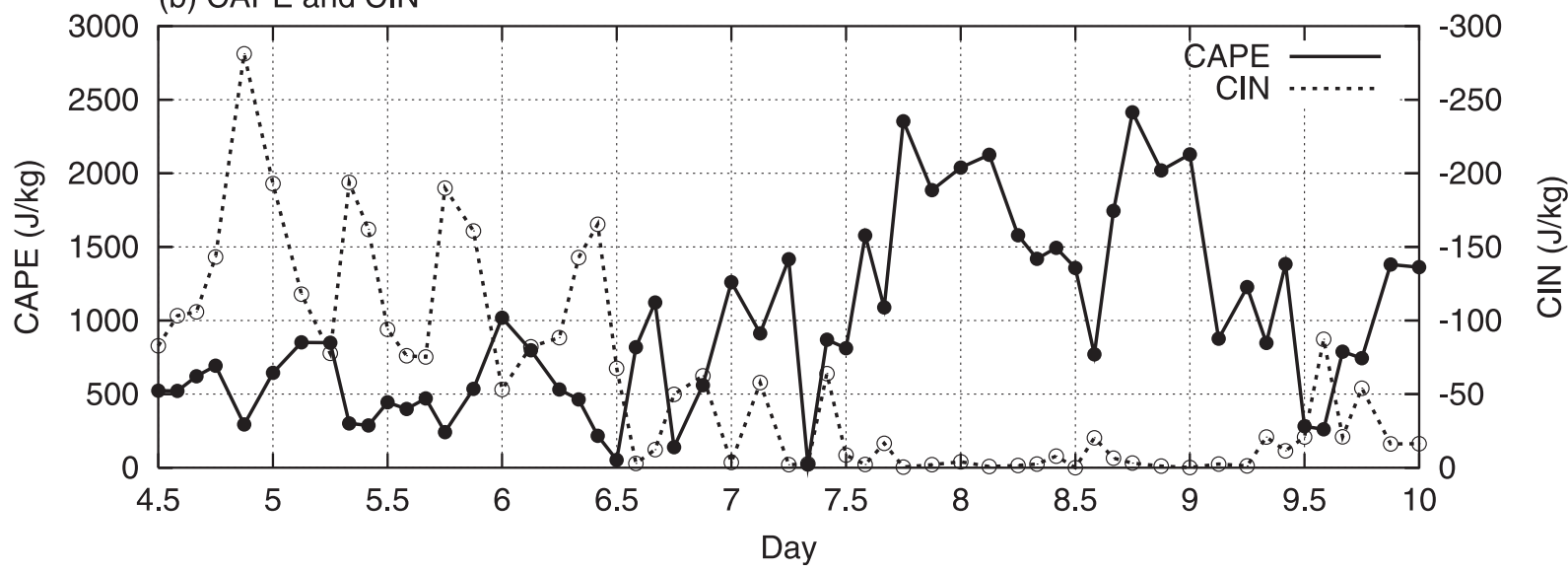

Fig. 4. Time series of the windshear and the atmospheric instability obtained from the soundings from July 5 to July 9, 2005. (a) Windshear (velocity difference) between heights of $500 \mathrm{~m}$ and $2000 \mathrm{~m}$, (b) CAPE (solid) and CIN (dashed); the abscissa is the date in July and the numbers correspond to 0000 JST.

Table 2. Model configuration.

\begin{tabular}{lll}
\hline & Coarse grid model & Fine grid model \\
\hline Grid volume & $2 \times 2 \times 0.3 \mathrm{~km}^{3}$ & $250 \times 250 \times 60 \mathrm{~m}^{3}$ \\
Effective grid cells & $240 \times 240 \times 40$ & $350 \times 410 \times 80$ \\
Domain center & $26.5 \mathrm{~N}, 127.9^{\circ} \mathrm{E}$ & $26.4 \mathrm{~N}, 128.0^{\circ} \mathrm{E}$ \\
Beginning time & $0300 \mathrm{JST}$ & $0600 \mathrm{JST}$ \\
Integration time & $18 \mathrm{~h}$ & $13 \mathrm{~h}$ \\
Initial condition & $u, v, \mathrm{P}, \mathrm{T}, \mathrm{RH}$ & $u, v, w, \mathrm{P}, \theta, q_{v}, q_{c}, q_{r}$ \\
Lateral forcing & as above & $u, v, \mathrm{P}, \theta, q_{v}$ \\
Lateral forcing interval & $3 \mathrm{~h}$ & $30 \mathrm{~min}$ \\
Topography data & $\mathrm{GTOPO} 30$ & $250-\mathrm{m}$ resolution $(\mathrm{GSI})$ \\
Land-use data & 1 -km resolution (GIS) & 100 -m resolution $(\mathrm{GIS})$ \\
Land surface temperature & $293 \mathrm{~K}$ (Initial value) & $293 \mathrm{~K}$ (Initial value) \\
Sea surface temperature & $301 \mathrm{~K}$ (Initial value) & $301 \mathrm{~K}$ (Initial value) \\
Turbulence scheme & 1.5 -order TKE & 1.5 -order TKE \\
Cloud physics & warm rain process & warm rain process \\
\hline
\end{tabular}

$u, v, w$ : wind components along the Cartesian coordinates

$\mathrm{P}$ : pressure, $\mathrm{RH}$ : relative humidity

T: temperature, $\theta$ : potential temperature

$q_{v}, q_{c}, q_{r}$ : mixing ratios of water vapor, cloud, and rain water. 
(a)Video images

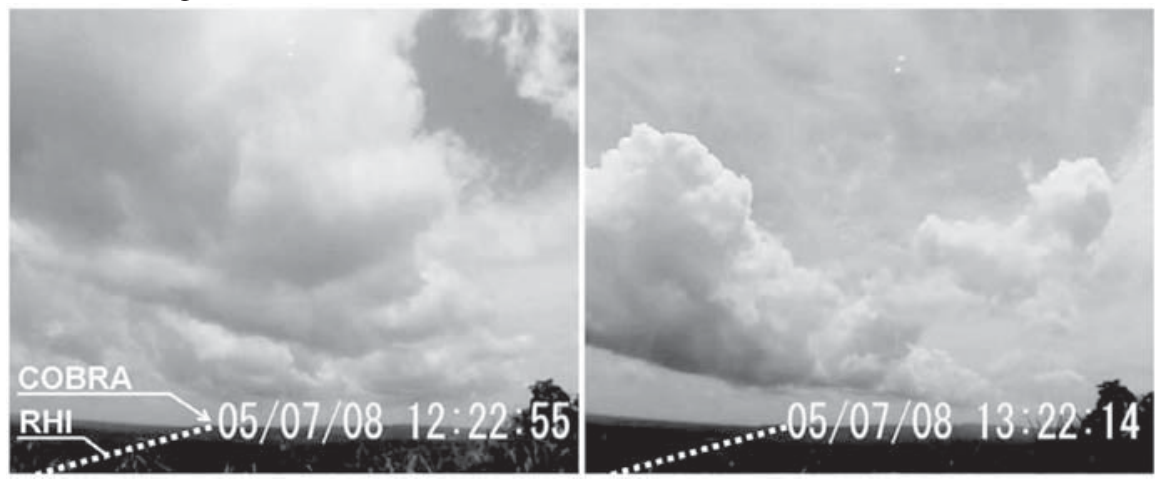

(b)GOES-9

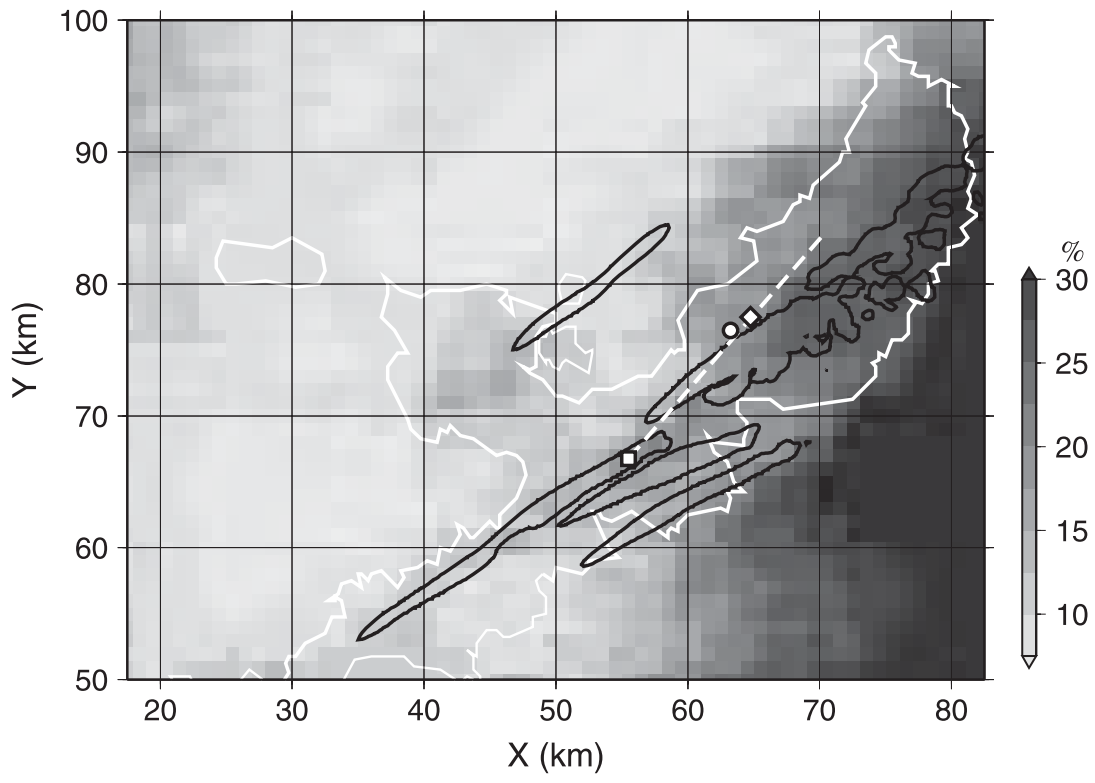

Fig. 5. (a) Video images at 1220 and 1320 JST on July 8, 2005. The dashed line displays the location of RHI. (b) GOES-9 visible image at 1330 JST. The shade indicates the albedo, and the contour shows the simulated cloud water path of $15 \mathrm{~g} \mathrm{~m}^{-2}$. The white dashed line shows the RHI, and the white contours indicate the shoreline. The symbols of square, diamond, and circle denote COBRA, Ogimi, and the video camera site, respectively.

the RHI at 1220 JST and across the RHI at 1320 JST. Figure 5b shows the GOES-9 visible image at $1330 \mathrm{JST}$ and the distribution of the simulated cloud water path averaged during 1320-1330 JST in CNTL. The cloud distributions in GOES-9 and CNTL seem to match. GOES-9 captured the roll cloud around COBRA with altostratus at the east edge, and the CNTL reproduced a line of clouds near COBRA. Figure 6 shows the vertical profiles of potential temperature $\theta$, mixing ratio of water vapor $q_{v}$, and wind in the soundings and CNTL at 1130-1530 JST. The simulated profiles are consistent with the observations, and provide evidence of the good reproducibility of the CBL.

Figures $7 \mathrm{a} 1$ and $7 \mathrm{a} 2$ show COBRA radar reflectivity factor $Z$ at 1250 and 1320 JST. The $Z$ images consist of three PPIs; echoes at radar ranges of 0-6, $6-15$, and beyond $15 \mathrm{~km}$ are derived from the PPIs at $8^{\circ}, 7^{\circ}$, and $1.4^{\circ} \mathrm{ELs}$, respectively. PPIs in this paper display moving echoes with absolute Doppler 

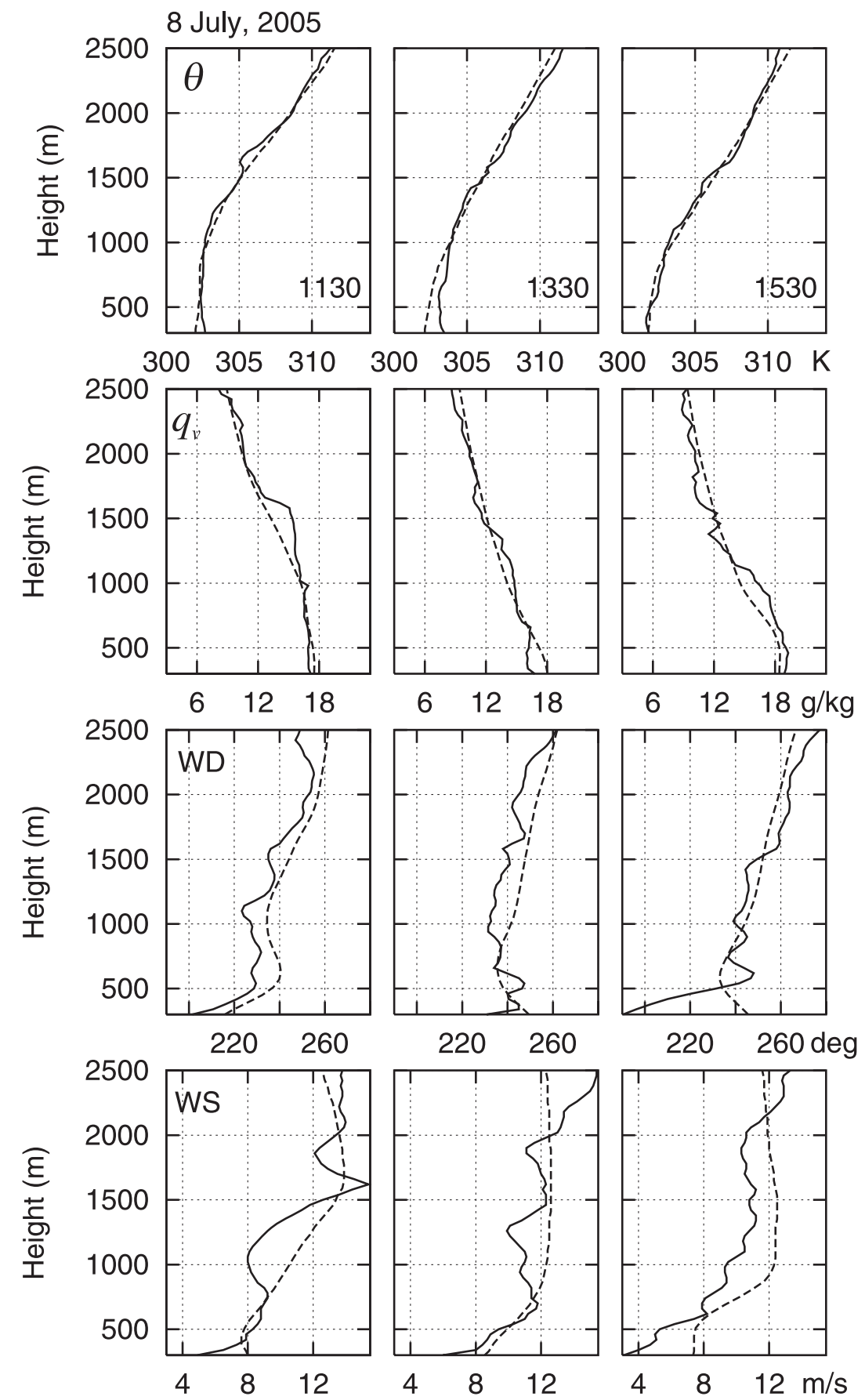

Fig. 6. Vertical profiles of $\theta, q_{v}$, wind direction (WD), and wind speed (WS) in the soundings and model at 1130-1530 JST on July 8, 2005; the solid line shows the soundings; the dashed line shows the model profiles above the sounding station.

velocities exceeding $1 \mathrm{~m} \mathrm{~s}^{-1}$ for the ground clutter elimination. Figure $7 \mathrm{a}$ shows that COBRA observed a weak $\mathrm{CAE}$ band $(<0 \mathrm{dBZ})$ around the RHI line and precipitation echoes $(>4 \mathrm{dBZ})$ at the leeward. Figure $7 \mathrm{~b}$ shows the horizontal distributions of the simulated $Z$ and mixing ratio of cloud water $q_{c}$ at a height of $1 \mathrm{~km}$ at 1230 and 1300 JST in CNTL. The simulated $Z$ incorporates Bragg 

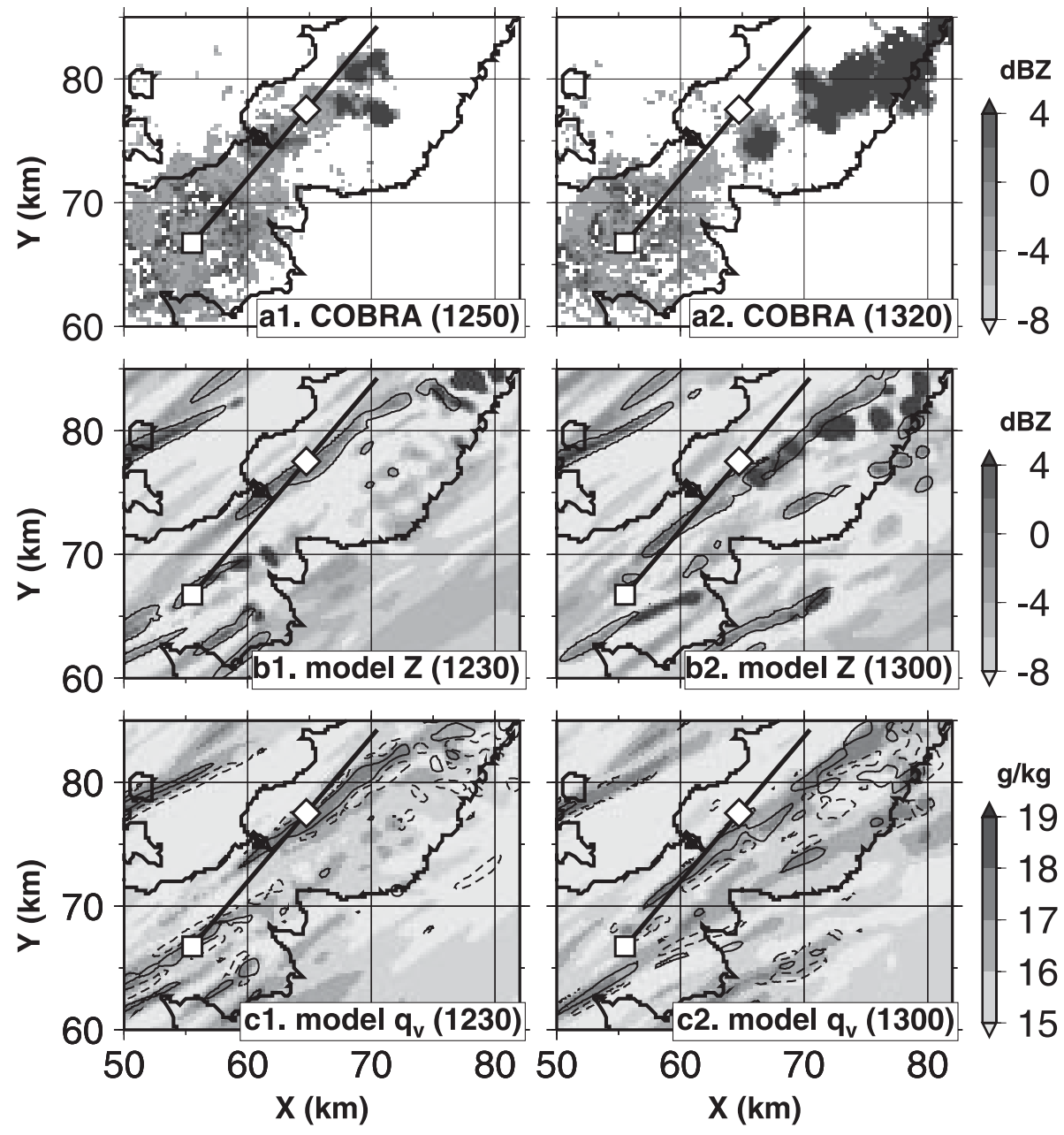

Fig. 7. (a) Horizontal distributions of COBRA $Z$ at 1250 and 1320 JST on July 8, 2005; this $Z$ distribution is a combination of PPIs at $1.4^{\circ}, 7^{\circ}$, and $8^{\circ}$ ELs and displays moving echoes of the absolute Doppler velocities exceeding $1 \mathrm{~m} \mathrm{~s}^{-1}$ for ground clutter elimination; square and diamond denote COBRA and Ogimi sites, respectively; the solid line displays the RHI. (b) Horizontal distributions of simulated $Z$ (shade) and $q_{c}$ at $0.1 \mathrm{~g} \mathrm{~kg}^{-1}$ (contour) at a height of $1 \mathrm{~km}$ at 1230 and $1300 \mathrm{JST}$. (c) Horizontal distributions of simulated $q_{v}$ (shade) and $w$ (contours) at a height of $1 \mathrm{~km}$ at 1230 and $1300 \mathrm{JST}$; the solid (dashed) contours indicate updrafts (downdrafts) of $1 \mathrm{~m} \mathrm{~s}^{-1}$.

scattering (see Appendix) and hydrometer scattering, assuming Rayleigh scattering and an exponential raindrop size distribution (Bringi and Chandrasekar 2001). Figure 7c shows the simulated $q_{v}$ and $w$ distributions. The CNTL shows $Z$ and $q_{c}$ lines across the RHI and precipitation $(>4 \mathrm{dBZ})$ to the leeward, as seen in the observations. A roll convection (a pair of updraft and downdraft stripes) uplifts moisture from the surface and produces a large $q_{v}$ line at the $Z$ line. Because C-band radars are insensitive to particulate scatterings from cloud droplets, the model suggests that COBRA detected
Bragg scattering from turbulent motions in moisture convergence areas.

To investigate roll initiations and the orographic effect, we conducted the FTM, and Fig. 8 shows the result of FTM at 1300 JST. Figures $8 \mathrm{a}-\mathrm{c}$ show the horizontal distributions of $w, \theta$, and $q_{v}$ at a height of $300 \mathrm{~m}$, respectively. Figure $8 \mathrm{a}$ shows that the flat land induces horizontal convective rolls along the land shape, and a distinct roll occurs on the RHI line. Figures $8 \mathrm{~b}$ and $\mathrm{c}$ show high $\theta$ $(>302.25 \mathrm{~K})$ and large $q_{v}\left(>18 \mathrm{~g} \mathrm{~kg}^{-1}\right)$ lines along the roll updrafts. Figure $8 \mathrm{f}$ shows large $q_{v}$ lines 


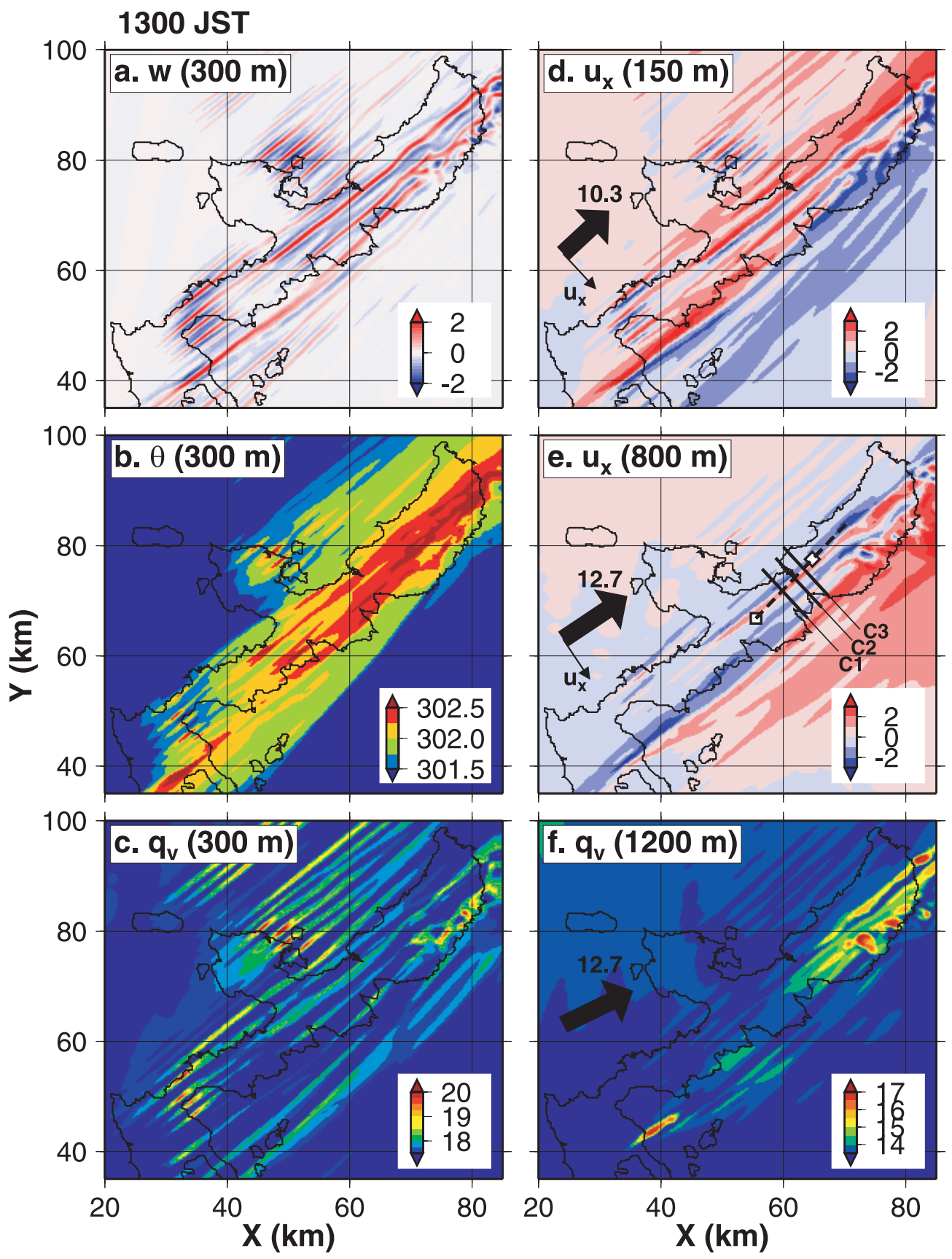

Fig. 8. FTM results at 1300 JST on July 8, 2005. (a)-(c) Horizontal distributions of $w, \theta$, and $q_{v}$ at a height of $300 \mathrm{~m}$. (d), (e) Horizontal distributions of the cross-wind component to the layer mean horizontal wind at a height of $150 \mathrm{~m}$ and $800 \mathrm{~m}$; the vector shows the mean wind with the value of the speed $\left(\mathrm{m} \mathrm{s}^{-1}\right)$; square and diamond denote COBRA and Ogimi sites, respectively; the dashed line denotes the RHI; the three solid lines labeled by $\mathrm{C} 1, \mathrm{C} 2$, and $\mathrm{C} 3$ are the locations of the vertical cross-sections in Fig. 9. (f) Horizontal distribution of $q_{v}$ at a height of $1200 \mathrm{~m}$; the vector shows the layer mean wind.

$\left(>14 \mathrm{~g} \mathrm{~kg}^{-1}\right)$ at a height of $1200 \mathrm{~m}$ at the northeast part of the island, suggesting that the flat land can induce the rolls transporting moisture up to a height of $1200 \mathrm{~m}$ at the lee parts of the rolls and no distinct moisture uplifts occur near the COBRA site. Figures 8d, e show the cross-wind component 


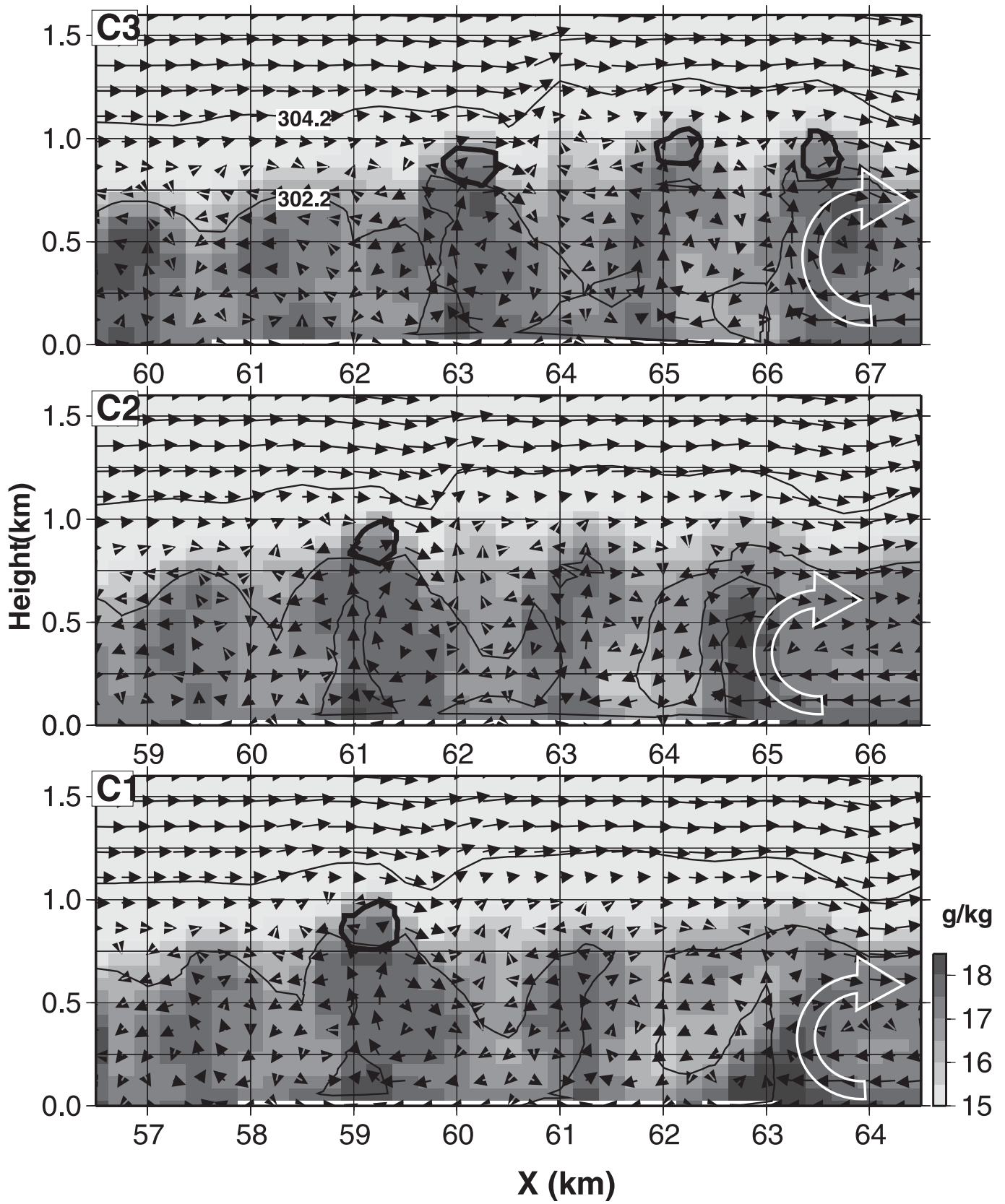

Fig. 9. Vertical cross-sections of $q_{v}$ (shade), $q_{c}$ (thick contour), $\theta$ (thin contour), and air motions (vector) in FTM at 1300 JST on July 8, 2005; the locations of the cross-sections are denoted in Fig. 8e; the thin contours show $\theta$ at 302.2 and $304.2 \mathrm{~K}$; the thick contour indicates $q_{c}$ of $0.1 \mathrm{~g} \mathrm{~kg}^{-1}$; the vectors show the air motion with $10 \mathrm{~m} \mathrm{~s}^{-1}$ per $1 \mathrm{~km}$ on the X-axis; the white line at the bottom denotes the land. The white arrows illustrate the sea-breeze circulation.

to the layer mean horizontal wind. The figures show convergent and divergent zones along the island at heights of 150 and $800 \mathrm{~m}$, respectively. This implies that the warmed island produces the sea-breeze circulation, but each roll produces local convergent and divergent lines. Figure 9 shows the vertical cross-sections of $q_{v}, \theta, q_{c}$, and air motions in FTM. The cross-sections $\mathrm{C} 1, \mathrm{C} 2$, and $\mathrm{C} 3$ are 


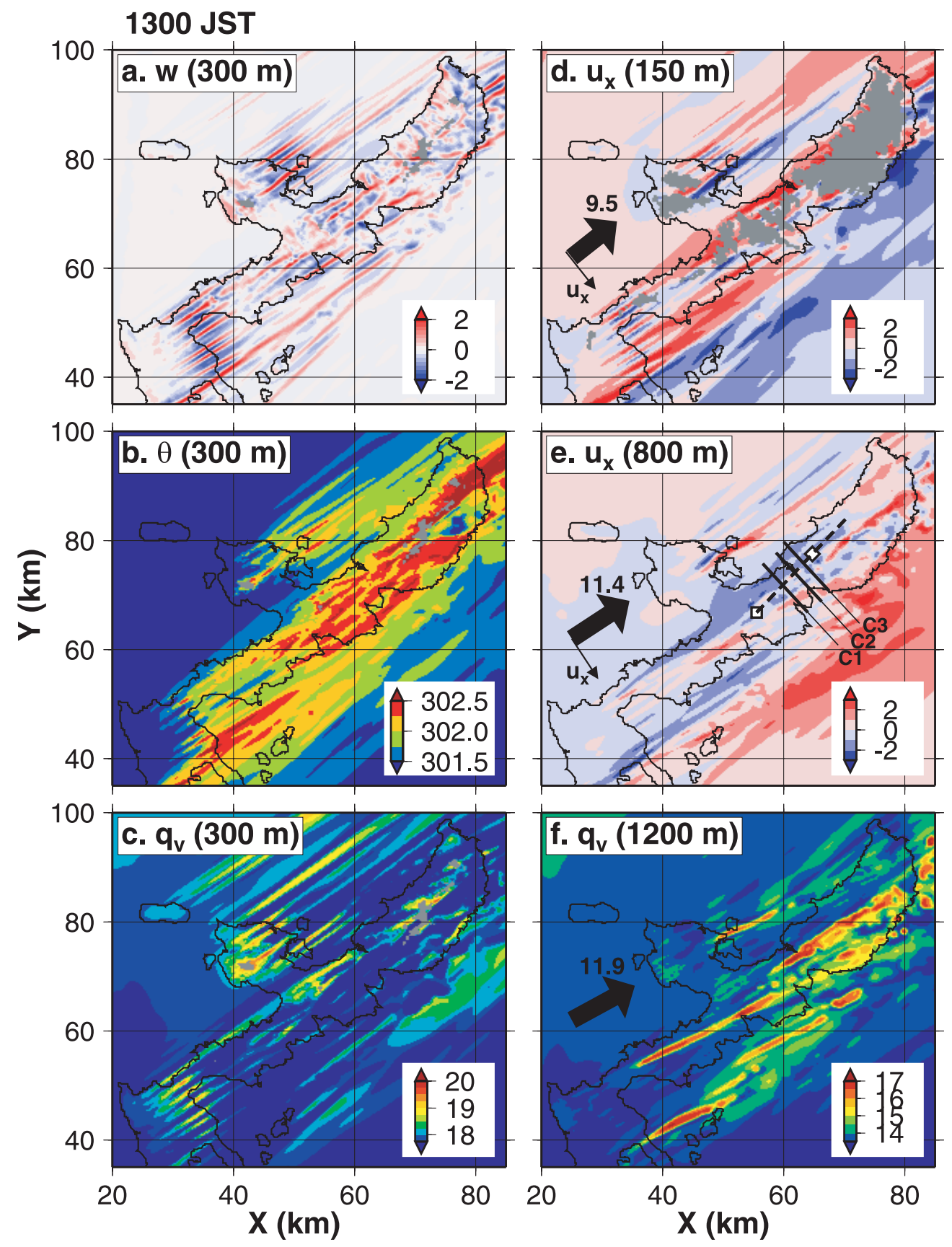

Fig. 10. As in Fig. 8, but the result of CNTL at 1300 JST on July 8, 2005. The gray shade in the panels (a)(d) represents the terrain.

shown in Fig. 8e. The figure shows that thermals induce circulations of $800-\mathrm{m}$ vertical scale; for example, a plume-like thermal updraft of $2 \mathrm{~m} \mathrm{~s}^{-1}$ forms at $61 \mathrm{~km}$ on the abscissa in $\mathrm{C} 2$ and interthermal downdrafts form along both sides of the thermal. The circulations converge moisture at the updrafts and transfer the moisture to the cloud condensation layer at a height of $800 \mathrm{~m}$, and then, weak clouds are produced by the circulations. The cross-sections also show the sea-breeze circulation at the east coast. The cross-sections $\mathrm{C} 1$ and $\mathrm{C} 3$ show that a moist sea wind merges to a thermal at $63 \mathrm{~km}$ and 

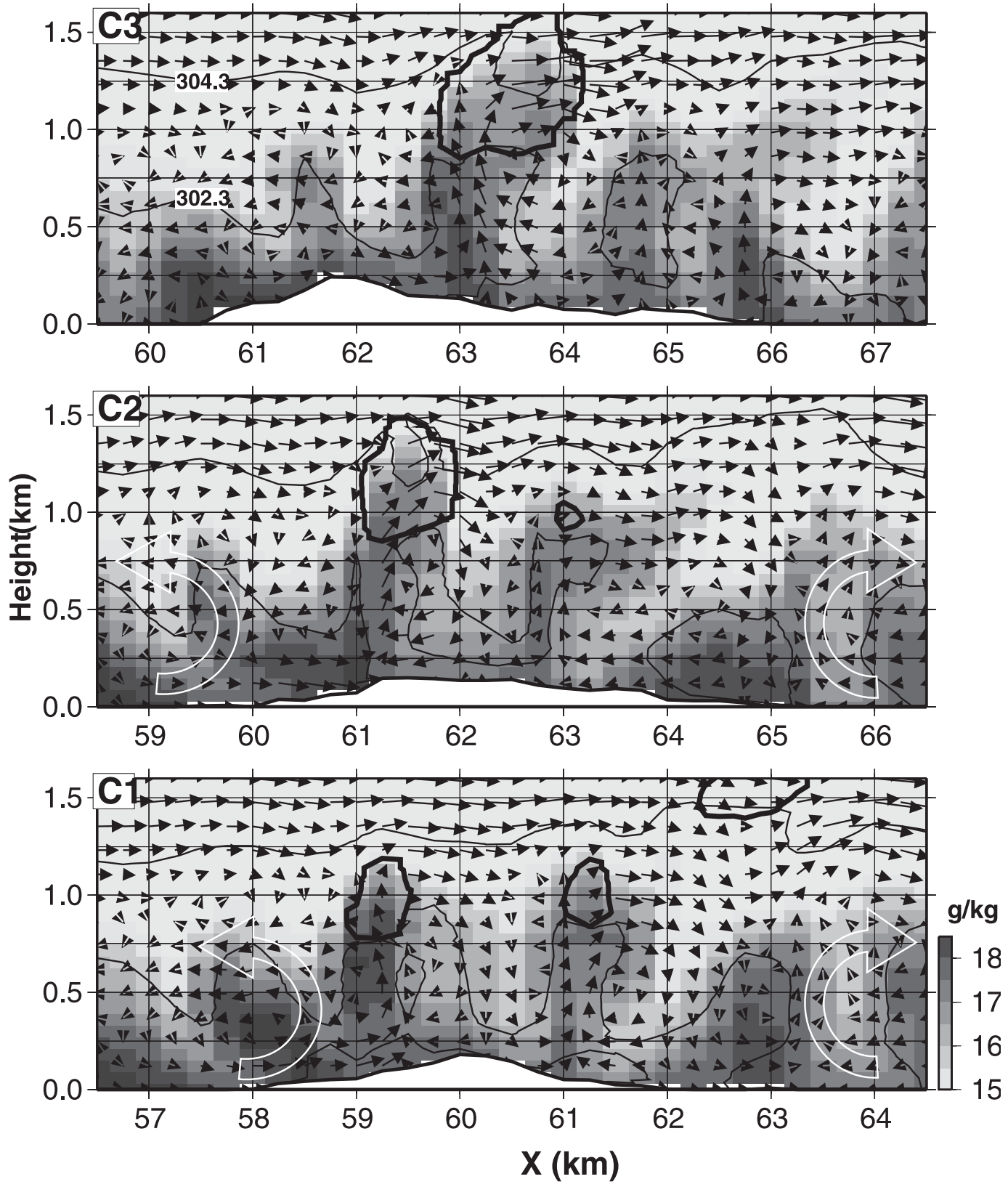

Fig. 11. As in Fig. 9, but the result of CNTL at 1300 JST on July 8, 2005.

$65 \mathrm{~km}$, respectively. A merging or collision of the sea-breeze and rolls often takes place in deep convection (Fovell 2005). The collision at $66 \mathrm{~km}$ enhances the moisture uplifting, and then, it produces a weak cloud by the circulation. The distinct large $q_{v}$ airmasses along the northeastern coast (Figs. 8c, f) seem to be supported by the merger or collision of the sea wind and the developed roll in the fully developed CBL.
Although the FTM produces a roll convection developing up to a height of $800 \mathrm{~m}$ at the area between COBRA and Ogimi sites, there is also evidence of a weak moisture uplift around the RHI line. Reconsidering the CNTL, Fig. 10 shows the result of CNTL at 1300 JST as in FTM (Fig. 8). Figure 10a shows that rolls occur at similar locations in FTM, but the terrain partly disturbs and uplifts the rolls. Figures 10b, c show high $\theta$ 

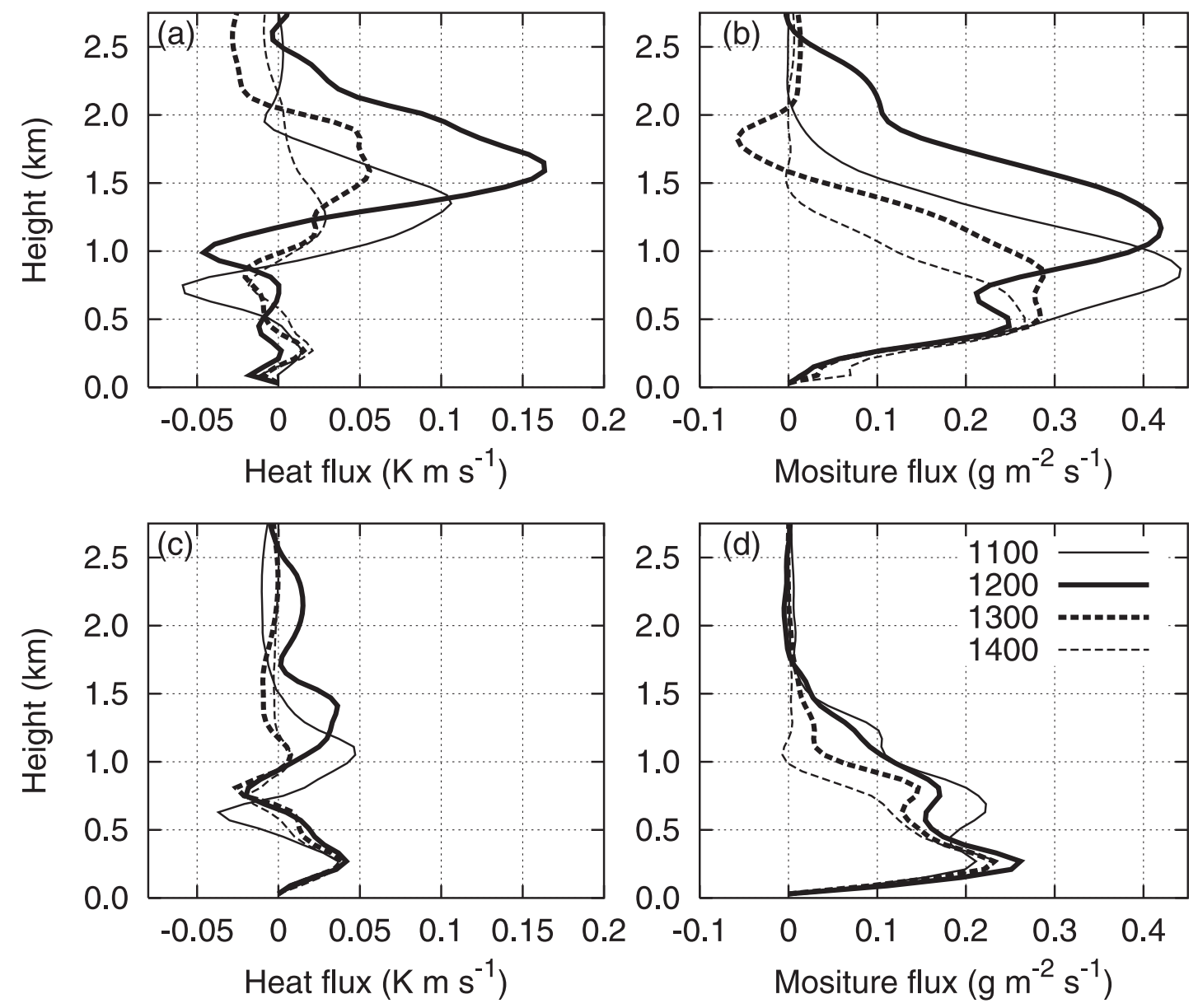

Fig. 12. Vertical profiles of (a) turbulent heat flux $\overline{w^{\prime} \theta^{\prime}}$ and (b) turbulent moisture flux $\overline{\rho w^{\prime} q_{v}^{\prime}}$ in CNTL at 1100-1400 JST on July 8, 2005. (c) Turbulent heat flux and (d) turbulent moisture flux in FTM.

$(>302.25 \mathrm{~K})$ and large $q_{v}\left(>18.5 \mathrm{~g} \mathrm{~kg}^{-1}\right)$ airmasses at the terrain peaks, as well as in the location of the roll updrafts, for example, along the RHI line and around the model grid of $(45 \mathrm{~km}$, $75 \mathrm{~km}$ ). This shows that the terrain peaks warm the near surface atmosphere and uplift the moisture. The layer mean winds (vectors in Figs. 10df) are about $1 \mathrm{~m} \mathrm{~s}^{-1}$ slower than FTM, implying that the terrain disturbs airflows above the island. The $q_{v}$ distribution at a height of $1200 \mathrm{~m}$ (Fig. 10f) suggests distinct orographical moisture uplift around the RHI line. The difference from Fig. 8f shows that the terrain contributes significantly to uplift the moisture and to produce the large $q_{v}$ lines of $16 \mathrm{~g} \mathrm{~kg}^{-1}$ corresponding to the CAE band along the RHI line. Figure 11 shows vertical crosssections $\mathrm{C} 1, \mathrm{C} 2$, and $\mathrm{C} 3$ at 1300 JST in CNTL and that the terrain drives and reinforces circulations.
Cross-section $\mathrm{C} 1$ shows a collision of a moist sea wind and a thermally induced circulation on the sloped coastal terrain. The sea wind brings a moist airmass up on the upslope at $58.5 \mathrm{~km}$ on the abscissa. The warmed land induces a thermal updraft of $2 \mathrm{~m} \mathrm{~s}^{-1}$ around $59.5 \mathrm{~km}$. The thermal uplifts a large $q_{v}$ airmass of $18 \mathrm{~g} \mathrm{~kg}^{-1}$ to the cloud condensation layer at a height of $800 \mathrm{~m}$, and then, the airmass rises up to a height of $1.2 \mathrm{~km}$ with the support of the latent heat release. The windshear (faster airflows above a height of $1 \mathrm{~km}$ ) the clockwise circulations in the figure and disturbs the counter circulations. Cross-section $\mathrm{C} 2$ shows the roll enhancement by the convection at the ridge top. The westerly sea wind transports moisture toward the ridge top. The merging of the sea wind and the roll on the ridge top produces an updraft of $2.5 \mathrm{~m} \mathrm{~s}^{-1}$ and a large $q_{v}$ airmass of $18 \mathrm{~g} \mathrm{~kg}^{-1}$ at the surface layer at 

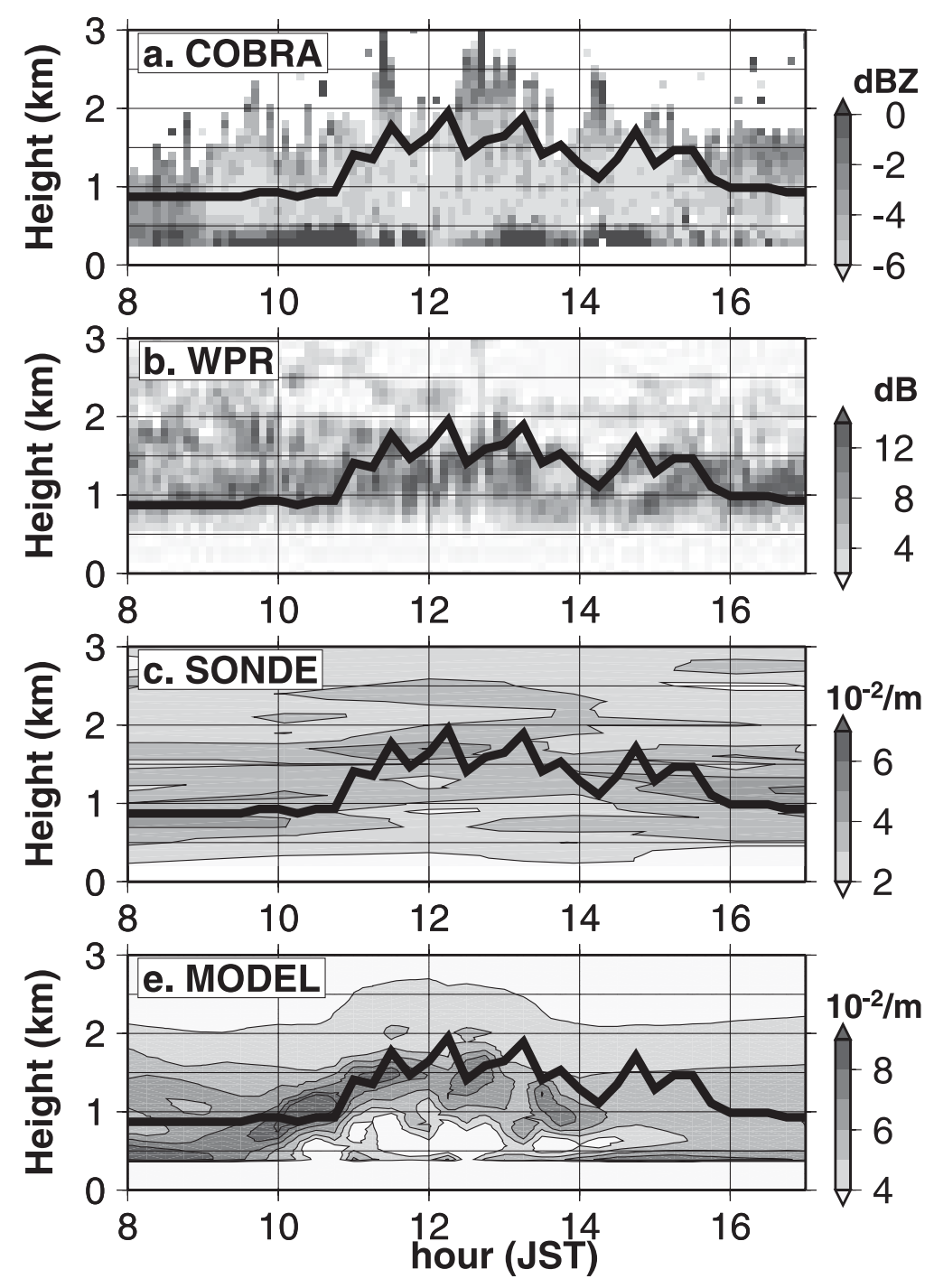

Fig. 13. Time-height cross-sections of (a) COBRA $Z$ at the radar range of $7 \mathrm{~km}$, (b) WPR SNR, (c) the refractivity gradient obtained from the sounding, and $(\mathrm{d})$ the refractivity gradient above the sounding station in CNTL on July 8, 2005. The solid line shows the cloud height determined from the positive peak of turbulent heat flux in CNTL.

$61 \mathrm{~km}$. Then the upward moisture transfer produces a deep roll cloud developing up to $1.5 \mathrm{~km}$ in height, and the lifted airmass flows with the wind. Consequently, a distinct clockwise circulation of $1200-\mathrm{m}$ vertical scale occurs on the ridge top. Cross-section $\mathrm{C} 3$ shows the roll on the down-sloped terrain. The downstream flow which passes over the ridge top collides with the roll. The collision produces an updraft of $2.8 \mathrm{~m} \mathrm{~s}^{-1}$ and a large $q_{v}$ airmass of $18 \mathrm{~g} \mathrm{~kg}^{-1}$ at $63 \mathrm{~km}$. The upward moisture motion develops and maintains the roll cloud. The faster westerly wind above a height of $1.25 \mathrm{~km}$ blows away the sinking airflow of the roll, and the neighboring thermal at $65 \mathrm{~km}$ disturbs the downward motion, ultimately generating a wave-like airflow. Thus, the CNTL shows the deeper cloud production compared to FTM, suggesting that the terrain is effective for the upward moisture transfers. In particular, the convection at the ridge top triggers the distinct roll cloud production.

Figure 12 shows vertical profiles of the turbulent heat flux $\overline{w^{\prime} \theta^{\prime}}$ and moisture flux $\overline{\rho w^{\prime} q_{v}^{\prime}}$ around the RHI in CNTL and FTM, where the prime denotes the perturbation from the spatial mean, the overbar 
(a) Video images

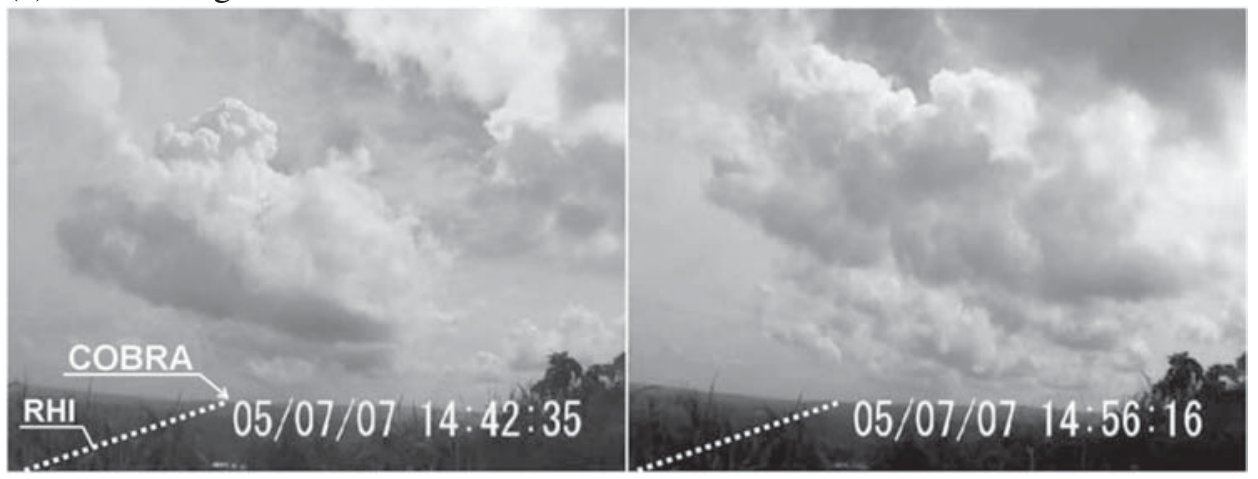

(b) GOES-9

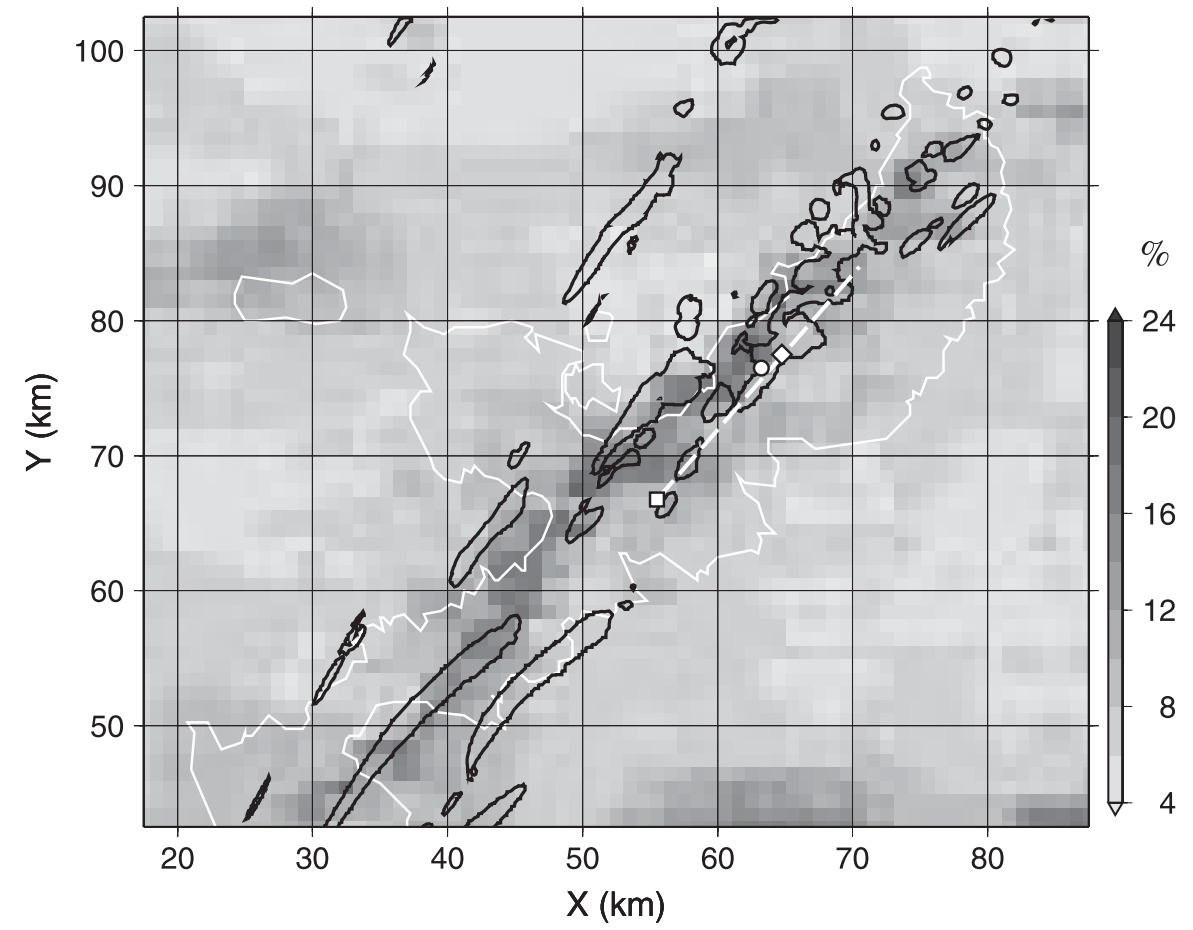

Fig. 14. As in Fig. 5, but (a) cloud pictures around 1450 JST and (b) GOES-9 at 1530 JST on July 7, 2005.

denotes the spatial mean, $\rho$ is the air density, and the flux is obtained from the grids above the land in the domain spanning $50-70 \mathrm{~km}$ along the Xaxis and $60-80 \mathrm{~km}$ along the $\mathrm{Y}$-axis. The small heat fluxes of $0.04 \mathrm{~K} \mathrm{~m} \mathrm{~s}^{-1}$ at a height of $250 \mathrm{~m}$ in FTM (Fig. 12c) represent a moist CBL (cf. Fig. 16 in Endo et al. 2008). Endo et al. (2008) showed $0.04 \mathrm{~K} \mathrm{~m} \mathrm{~s}^{-1}$ near the surface in the moist CBL above a humid, flat terrain and $0.2 \mathrm{~K} \mathrm{~m} \mathrm{~s}^{-1}$ in the dry CBL around noon. Both the heat and moisture fluxes in CNTL show distinct peaks above a height of $800 \mathrm{~m}$ (Figs. 12a, b), whereas the FTM does not show the distinct peaks (Figs. 12c, d). This implies that the terrain enhances roll cloud development. The heat fluxes in CNTL at 1100 and 1200 JST show positive peaks around a height of $1.5 \mathrm{~km}$. Note that the peaks represent cool air sinks (negative $w^{\prime}$ and negative $\theta^{\prime}$ ) due to evaporation at the top of the circulations (not shown). Accordingly, this paper regards the positive peak as the mean 

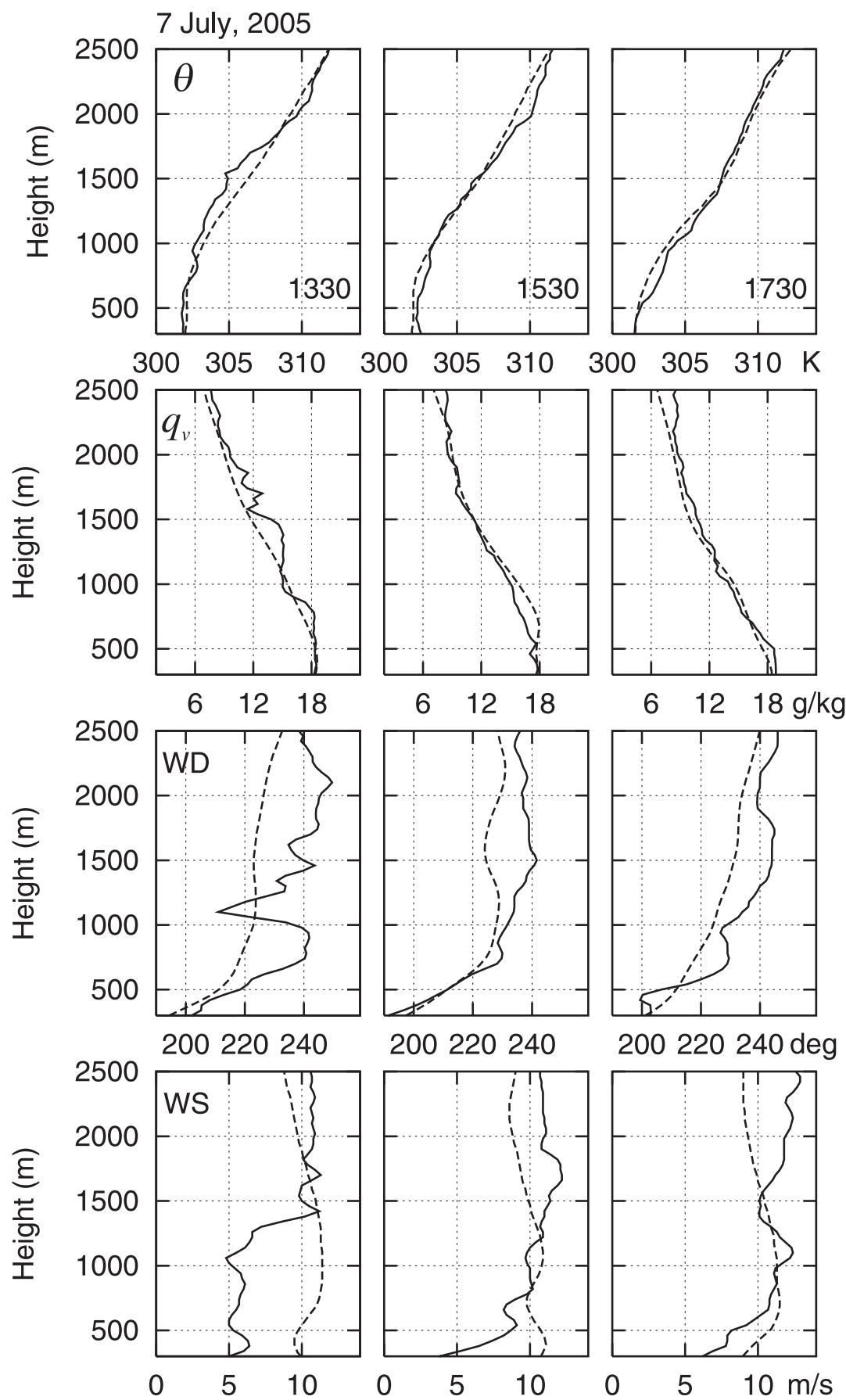

Fig. 15. As in Fig. 6, but at 1330-1530 JST on July 7, 2005.

height of cloud tops. The distinct positive moisture fluxes of $0.4 \mathrm{~g} \mathrm{~m}^{-2} \mathrm{~s}^{-1}$ around a height of $1 \mathrm{~km}$ in CNTL represent upward moisture transfers by the roll convection.

Figure 13 shows the time-height cross-sections of
COBRA $Z$ at the range of $7 \mathrm{~km}$, WPR signal-tonoise ratio (SNR), the refractivity gradient $(d N / d z)$ obtained from the soundings, and the refractivity gradient above the sounding station in CNTL. The intense layers of WPR SNR and refractivity gradi- 
ent commonly represent CBL depth or cloud base (Grimsdell and Angevine 1998). The figure also shows mean cloud height around the RHI, as determined from the positive peak of $\overline{w^{\prime} \theta^{\prime}}$ in CNTL. Since the intense layer of COBRA $Z$ coincides with the model cloud height, COBRA observes cloud tops as the intense CAE layer. The intense layers of COBRA $Z$, WPR SNR, and the refractivity gradients show diurnal variations with peaks appearing around noon, that is, the CBL evolves in the morning. Endo et al. (2008) showed that a rapid CBL formation in the morning is a characteristic of a dry $\mathrm{CBL}$, and this suggests that the moist CBL on 8 July has the dry CBL characteristic.

\subsection{Cellular convection on July 7, 2005}

Shallow cumulus clouds appeared along the island in the afternoon of July 7, and COBRA observed several bell-shaped CAEs on the RHI during 1400-1500 JST. Figure 14a shows cloud pictures around 1450 JST. The video camera recorded a distinct cumulus at 1442 JST and the cumulus street deviated westwardly at 1456 JST. Figure 14b shows the GOES-9 visible image at 1530 JST, and the simulated cloud water path averaged during 15201530 JST in CNTL. GOES-9 captured a distinct cloud street along the island, and this cloud street coincides well with the cloud water path distribution. Figure 15 shows vertical profiles of $\theta, q_{v}$, and the wind in the soundings and CNTL at 1330-1730 JST. The profiles show that the model reproduced meteorological quantities fairly well, but the sonde at 1330 JST rose in a shallow cloud, whereas the model produced few clouds. The soundings show southerly surface winds $\left(190^{\circ}-200^{\circ}\right)$ and a moist $\left(18 \mathrm{~g} \mathrm{~kg}^{-1}\right)$ surface layer compared to July 8 .

Figure 16 shows PPIs at $7^{\circ} \mathrm{EL}$ of COBRA $Z$ at 1440 and 1450 JST and the result of CNTL at 1500 JST. COBRA $Z$ (Fig. 16a) shows CAE bands of $-6-0 \mathrm{dBZ}$ along the RHI line and to the west of COBRA, and a ring-shaped CAE representing cumulus appeared above the sea to the north (grid $59 \mathrm{~km}, 75 \mathrm{~km}$ ) at 1450 JST. A thermal cellular convection generates a ring-shaped CAE on a PPI and a bell-shaped CAE on a RHI because of a drastic refractivity variation at the thermal edge and uniform $q_{v}$ at the inside of the thermal (Hardy and Ottersten 1969). The strong echo (indicated by the dark shade) near COBRA is a biological CAE; the echo indicated strong reflectivities of $30 \mathrm{dBZ}$ and typical biological polarimetric signatures (not shown) (Minda et al. 2008). COBRA rarely ob- served biological CAEs above a height of $500 \mathrm{~m}$ during the observation period. Figure $16 \mathrm{~b}$ shows horizontal distributions of $Z$ and $q_{c}$ at heights of 800 and $1400 \mathrm{~m}$ in CNTL; the height of 800 (1400) m corresponds to a radar range of $4(8) \mathrm{km}$ on the PPI. The simulated $Z$ distribution appears to match the observed CAE distributions. For example, $Z$ around $0 \mathrm{dBZ}$ with $q_{c}$ to the west of COBRA at a height of $800 \mathrm{~m}$ (Fig. 16b1) and a $Z$ line around $0 \mathrm{dBZ}$ along the RHI line at a height of $1400 \mathrm{~m}$ (Fig. 16b2) coincide with this observation. A cellular $q_{c}$ (cumulus) distribution above the sea to the north at a height of $1400 \mathrm{~m}$ in the model (Fig. 16b2) corresponds to the ring-shaped CAE in the observation (Fig. 16a2), but the simulated $Z$ indicates a vague ring-shape because the model grid of $250 \mathrm{~m}$ is too coarse to show the small scalecumulus $(\sim 2 \mathrm{~km})$ as a ring-shaped $Z$. Figure $16 \mathrm{c}$ shows horizontal distributions of the simulated $q_{v}$ and $w$ at heights of 800 and $1400 \mathrm{~m}$, respectively. At a height of $800 \mathrm{~m}$ (Fig. 16c1), weak roll-like circulations (pairs of updraft and downdraft of $0.5 \mathrm{~m} \mathrm{~s}^{-1}$ ) with large $q_{v}$ lines of $18 \mathrm{~g} \mathrm{~kg}^{-1}$ appear behind the terrain peaks, suggesting that the terrain uplifts the rolls and moisture following the terrain shape. At a height of $1400 \mathrm{~m}$ (Fig. 16c2), cellular large $q_{v}$ airmasses $\left(>14 \mathrm{~g} \mathrm{~kg}^{-1}\right)$ with a cellular convection (an updraft core surrounded by a downdraft) can be found to the north of COBRA. The convection appears above the lee part of the lifted rolls, suggesting that the rolls transport moisture to the cloud condensation level and trigger the cellular convection. Figure 17a shows RHIs of COBRA $Z$ around 1440 JST; it displays echoes moving away from COBRA with Doppler velocities faster than $0.5 \mathrm{~m} \mathrm{~s}^{-1}$ after ground clutter elimination. COBRA observed some bell-shaped CAEs of 2-km horizontal scale and a CAE at $11-\mathrm{km}$ radar range at 1445 JST, corresponding to the distinct cumulus in the video image at 1442 JST (Fig. 14a). The CAEs developed while approaching the steep mountain at a $12-\mathrm{km}$ range, particularly the rapidly ascending echo (labeled by A), up to a height of $2.5 \mathrm{~km}$ at a range of $14-15 \mathrm{~km}$ at $1445 \mathrm{JST}$. Figures $17 \mathrm{~b}-\mathrm{d}$ show the vertical cross-sections of simulated $Z, q_{v}$, and $\theta$ around $1450 \mathrm{JST}$ in CNTL. The model produces a bell-shaped $Z$ rising from the surface. The bell-shaped $Z$ develops at places of moisture uplifts, at $57 \mathrm{~km}$ and $62 \mathrm{~km}$ on the abscissa, which correspond to the updrafts of roll-like circulations and show high $\theta(>302 \mathrm{~K})$ and large $q_{v}\left(>18 \mathrm{~g} \mathrm{~kg}^{-1}\right)$ airmasses near the surface. Particularly, the abun- 

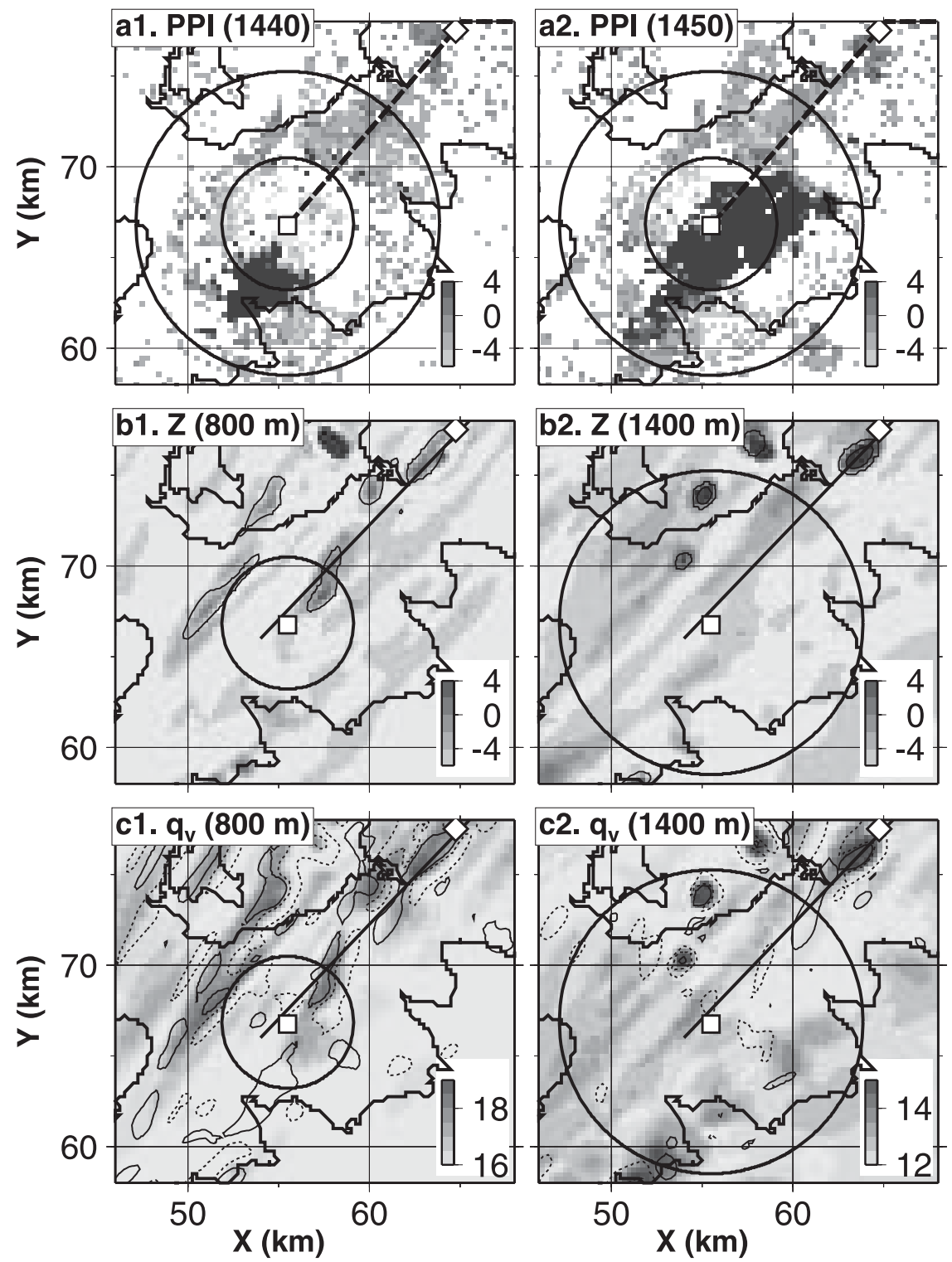

Fig. 16. Horizontal distributions of COBRA $Z$ and CNTL on July 7, 2005. (a) COBRA PPIs at $7^{\circ}$ EL at 1440 and 1450 JST; the PPI displays moving echoes of the absolute Doppler velocities exceeding $1 \mathrm{~m} \mathrm{~s}^{-1}$; square and diamond denote COBRA and Ogimi sites, respectively; the dotted line shows the RHI; the circles denote the radar ranges corresponding to the heights of $800 \mathrm{~m}$ and $1400 \mathrm{~m}$. (b) Model $Z$ (shade) and $q_{c}$ of 0.1 and $1 \mathrm{~g} \mathrm{~kg}^{-1}$ (contours) at height of $800 \mathrm{~m}$ and $1400 \mathrm{~m}$ at $1500 \mathrm{JST}$; the solid line shows the location of vertical cross-section in Fig. 17. (c) Model $q_{v}$ (shade) and $w$ (contours) at height of $800 \mathrm{~m}$ and $1400 \mathrm{~m}$ at $1500 \mathrm{JST}$; the solid (dot) contour shows the updraft (downdraft) of $0.5 \mathrm{~m} \mathrm{~s}^{-1}$.

dant $q_{v}$ uplift at $62 \mathrm{~km}\left(19 \mathrm{~g} \mathrm{~kg}^{-1}\right.$ at $2.5 \mathrm{~m} \mathrm{~s}^{-1}$ updraft) triggers a strong convection developing up to a height of $2 \mathrm{~km}$ (labeled by $\mathrm{A}^{\prime}$ ), as seen in the RHI at 1445 JST.

Figure 18 shows the result of FTM all over the island at 1430 JST as in Fig. 8. Figure 18a shows that the south-southwesterly surface wind traveling over the warmed flat land induces rolls as seen on 8 July, where it seems to require about ten kilometers land distance before roll signatures (pairs of updraft and downdraft) appear at a height of $300 \mathrm{~m}$. The wind induces a weak roll in the first half range 

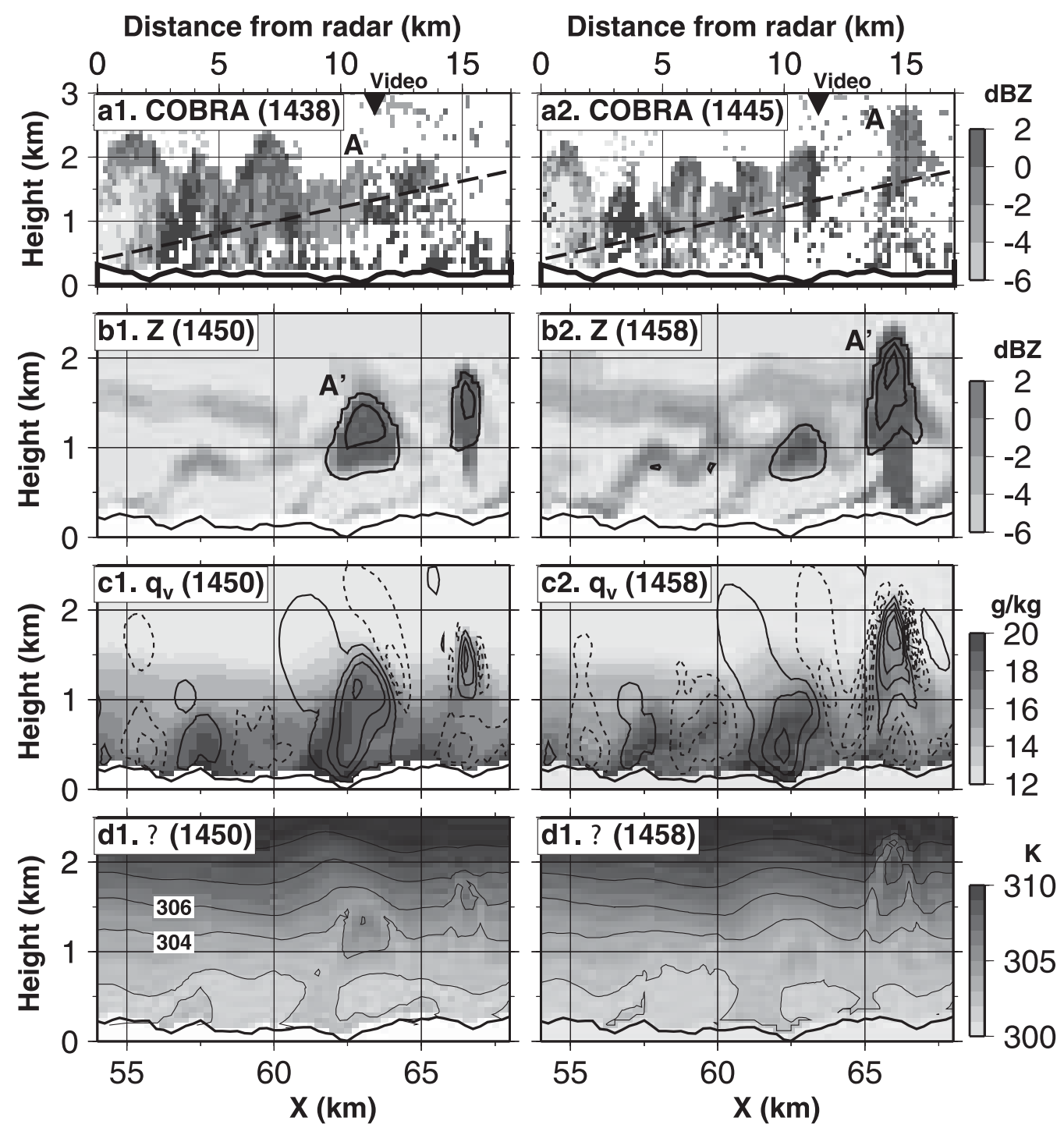

Fig. 17. Vertical distributions of COBRA $Z$ and CNTL on July 7, 2005. (a) COBRA RHIs at 1438 and 1445 JST on July 7, 2005; the label A denotes a rapidly developing echo; the RHI displays echoes of the Doppler velocities exceeding $0.5 \mathrm{~m} \mathrm{~s}^{-1}$; the solid curve at the bottom denotes the terrain; the dashed line denotes the PPI plane at $7^{\circ}$ EL. (b) Vertical distributions of simulated $Z$ (shade) and $q_{c}$ of $0.5,1.5$, and $2.5 \mathrm{~g} \mathrm{~kg}^{-1}$ (contours) at 1450 and 1458 JST in CNTL. The label $\mathrm{A}^{\prime}$ denotes a rapidly developing echo; (c) Vertical distributions of $q_{v}$ (shade) and $w$ (contours); the solid contour shows the updrafts of $0.5,1.5,2.5$, and $3.5 \mathrm{~m} \mathrm{~s}^{-1}$; the dashed contour indicates the downdrafts of 0.5 and $1 \mathrm{~m} \mathrm{~s}^{-1}$. (d) Vertical distribution of $\theta$.

of the RHI because of the short land distance from the coast (several kilometers inland), which indicates a weak updraft line and no distinct downdrafts. The roll develops on the second half range of the RHI, indicating the roll signature. Figures $18 \mathrm{~b}$ and $\mathrm{c}$ show that high $\theta$ and large $q_{v}$ lines (302.5 $\mathrm{K}$ and $19 \mathrm{~g} \mathrm{~kg}^{-1}$ ) along the roll updrafts, that is, thermals induce the rolls and uplift the moisture. Figure $18 \mathrm{c}$ shows that small islands around the grid of $(45 \mathrm{~km}, 40 \mathrm{~km})$ produce a large $q_{v}$ line reaching to the RHI line behind the islands, and it is considered to moisten the CBL around the RHI line. Figure 18b shows that the land warms the lowest atmosphere. Figure 18d (18e) shows a convergent (divergent) zone at 150 (800) $\mathrm{m}$ height along the island, and it implies that the warmed 

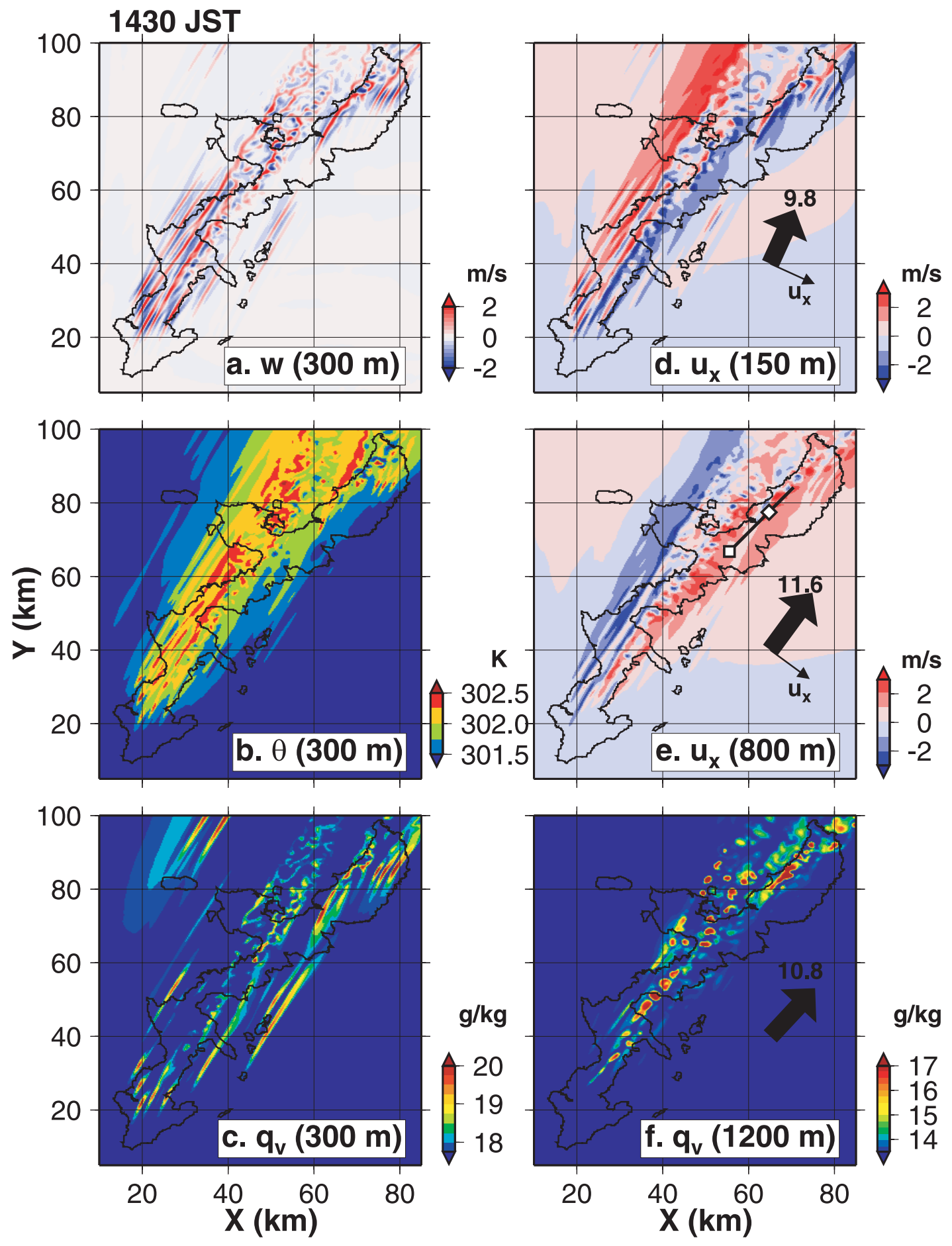

Fig. 18. As in Fig. 8, but the result of FTM at 1430 JST on July 7, 2005.

land generates the sea-breeze circulation. Figure $18 \mathrm{f}$ shows cellular large $q_{v}$ airmasses of $17 \mathrm{~g} \mathrm{~kg}^{-1}$ above the convergent zone at a height of $1200 \mathrm{~m}$. The cellular convection seems to be initiated in the coastal area. The sea-breeze transporting moisture inland is considered to reinforce moisture convergences and to trigger the convection along the complicated shoreline. 

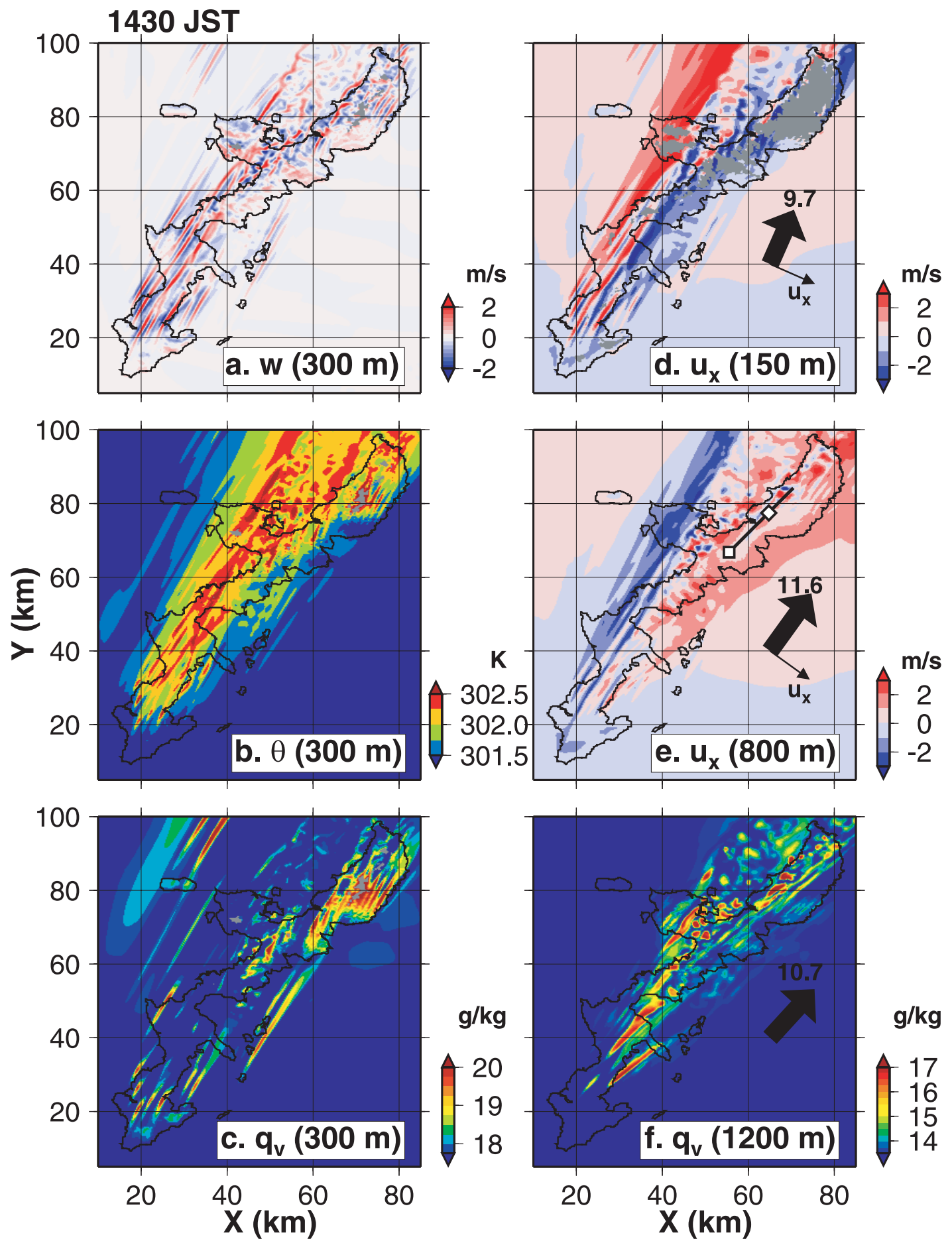

Fig. 19. As in Fig. 8, but the result of CNTL at 1430 JST on July 7, 2005. The gray shade in the panels (b)(d) represents the terrain.

Figure 19 shows the result of CNTL at 1430 JST and the similar result in FTM. The warmed land induces rolls and a convergent zone above the island (Figs. 19a-e). The layer mean horizontal winds at 150, 800, and $1200 \mathrm{~m}$ (vectors in Figs. 19d-f) show the same velocities in FTM. This sug- 

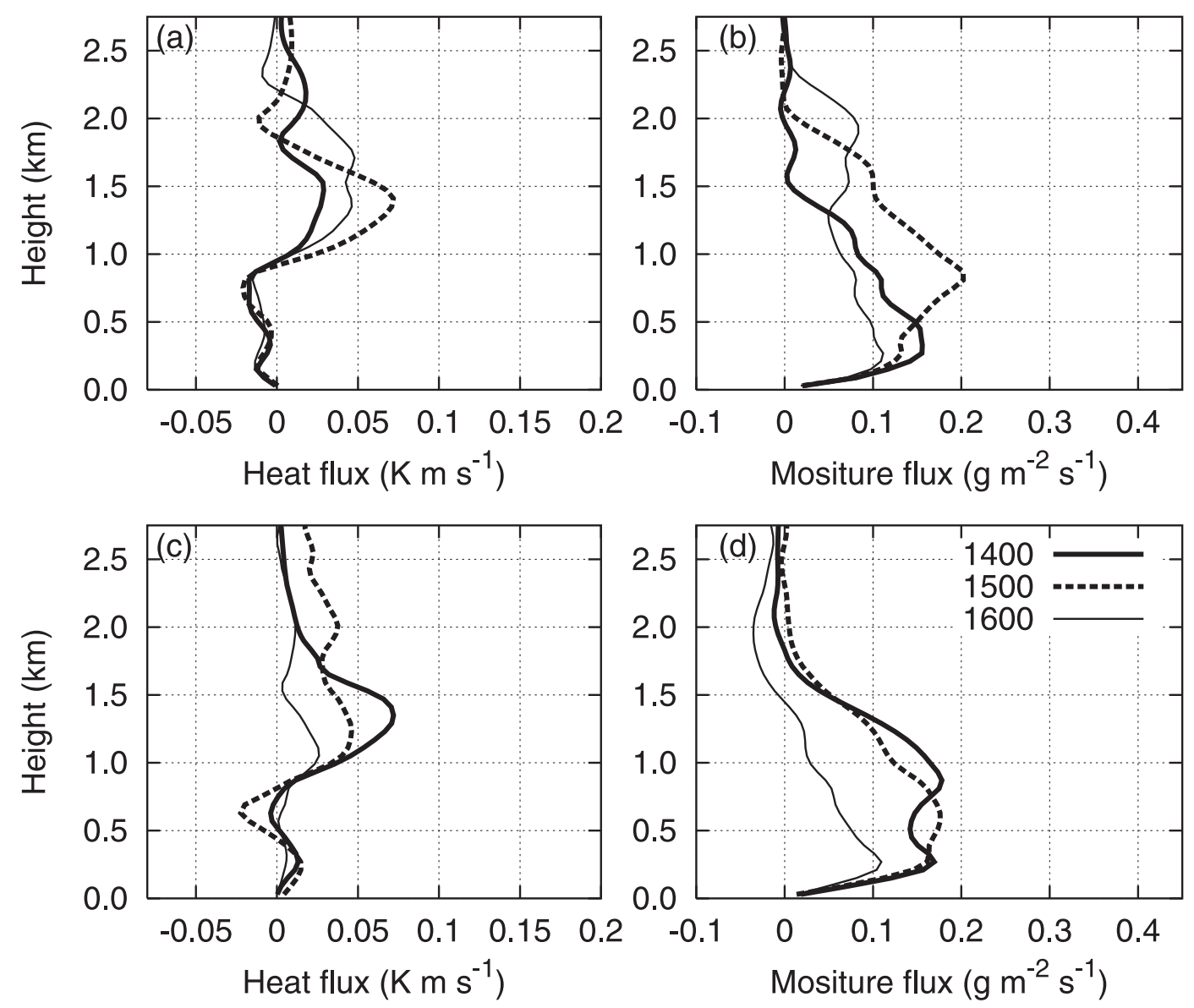

Fig. 20. As in Fig. 12, but at 1400-1600 JST on July 7, 2005.

gests that the terrain allows the air to flow smoothly. The differences from FTM are high $\theta$ $(>302 \mathrm{~K})$ and large $q_{v}\left(>19 \mathrm{~g} \mathrm{~kg}^{-1}\right)$ airmasses above the high mountains at a height of $300 \mathrm{~m}$ in the northern part (Figs. 19b, c). The CNTL produces distinct $q_{v}$ lines of $15 \mathrm{~g} \mathrm{~kg}^{-1}$ at a height of $1200 \mathrm{~m}$ in the northern part in addition to cellular large $q_{v}$ airmasses (Fig. 19f), and the $q_{v}$ lines correspond to the observed CAE lines along the RHI line (cf. Fig. 16a). The CNTL shows that the high elevation terrain is effective to warm the near surface atmosphere and for the moisture uplifts, and the south-southwesterly wind exceeds the moist CBL characteristic in the northern part.

Figure 20 shows the vertical profiles of turbulent heat and moisture fluxes in CNTL and FTM as in Fig. 12. Both the CNTL and FTM show similar flux profiles. This shows that the terrain contributed slightly to the turbulent energy transfers on 7 July.
The heat fluxes at a height of $250 \mathrm{~m}$ in FTM (Fig. 20c) show smaller fluxes $\left(0.01 \mathrm{~K} \mathrm{~m} \mathrm{~s}^{-1}\right)$ than those on 8 July $\left(0.04 \mathrm{~K} \mathrm{~m} \mathrm{~s}^{-1}\right.$ in Fig. 12c), and the small heat flux (nearly zero) suggests a well moistened CBL. Figure 21 shows the time-height crosssections of COBRA $Z$, WPR SNR, and the refractivity gradients by the sounding and CNTL as in Fig. 13. Although the soundings and WPR vaguely show CBL evolution, COBRA and CNTL show the slowly evolving CBL until 1500 JST. This slower evolution also suggests the moist CBL (cf. Fig. 4 in Endo et al. 2008). Endo et al. (2008) pointed out that a large latent heat flux from a humid surface $\left(\sim 500 \mathrm{~W} \mathrm{~m}^{-2}\right)$ and weak sensible heat flux $\left(\sim 150 \mathrm{~W} \mathrm{~m}^{-2}\right)$ characterize the moist CBL, and they slowly form the CBL until the late afternoon. This study showed a similar latent heat flux (450 $\mathrm{W} \mathrm{m}^{-2}$ at $1400 \mathrm{JST}$ ) and sensible heat flux (220 $\mathrm{W} \mathrm{m}^{-2}$ ) (not shown). 

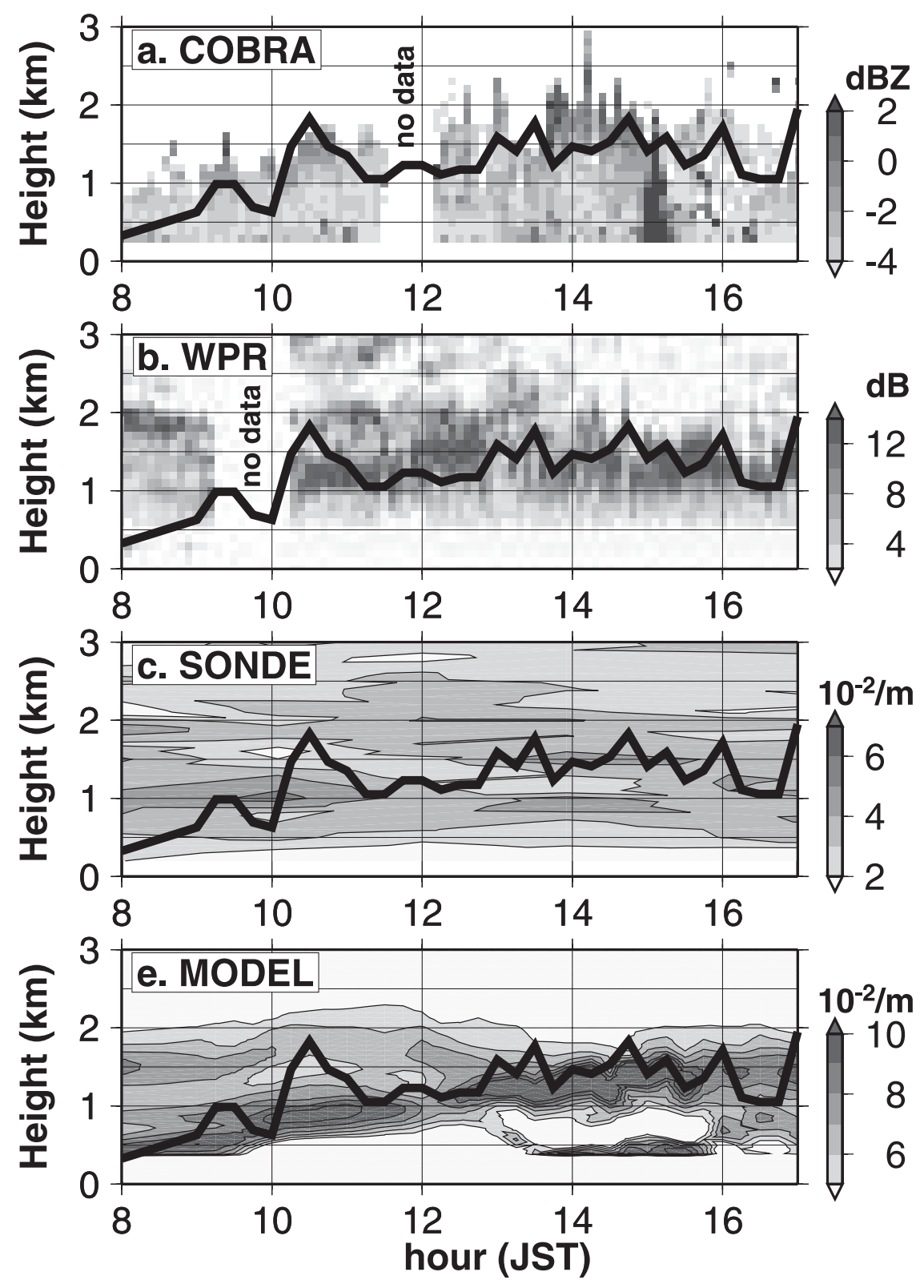

Fig. 21. As in Fig. 13, but on July 7, 2005.

\section{Summary and discussion}

This paper attempts to improve the current understanding of moist CBL evolution and cloud initiation above Okinawa Island using a C-band precipitation radar (COBRA) and a cloud resolving model (CReSS). We conducted an intensive observation on Okinawa Island in early July 2005. COBRA observed CAEs within a $10-\mathrm{km}$ radar range, and the CAE height showed diurnal variations. To investigate the nature of the CAEs and the capability of the CBL profiling by COBRA, we performed CReSS with 250-m horizontal resolution for the two cases: a distinct roll cloud on July 8 and a cumulus street on 7 July. The FTM was also performed to understand the orographic effect on cloud initiations. On the basis of the results, we find strong consistencies between the simulated $Z$ and observed CAE distributions. The model vertical profiles above the sounding station are in accordance with 


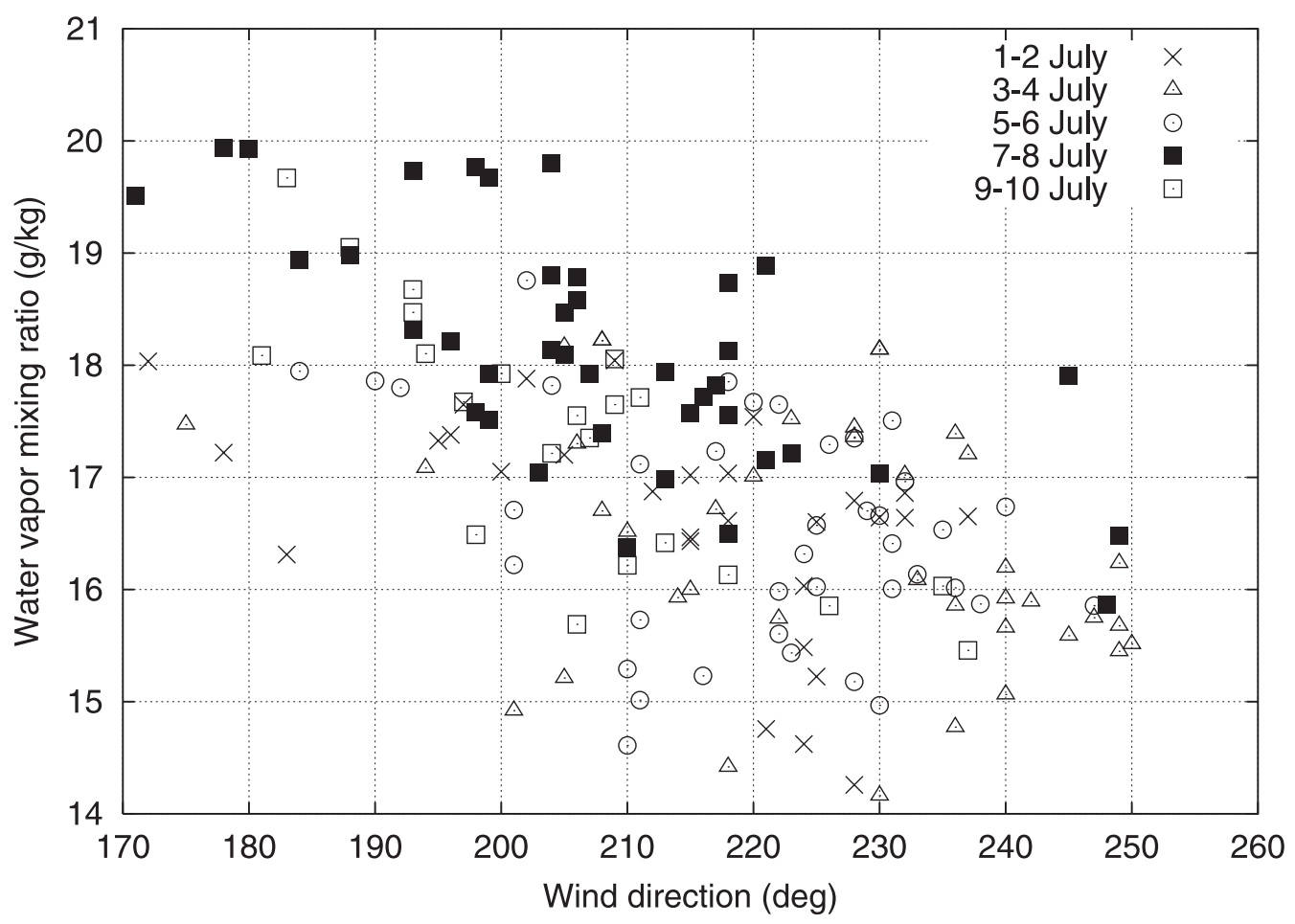

Fig. 22. The relationship between the wind direction and $q_{v}$ at heights of $300 \mathrm{~m}$ and $500 \mathrm{~m}$ obtained from the soundings from July 1 to July 10, 2005.

the soundings, and the CBL evolutions in the model agree with the diurnal variations of the intense CAE layer of COBRA. Therefore, the model successfully reproduced meteorological parameters to describe the dynamics of the CBL and the nature of CAE. The model suggests that the CAEs form as a result of turbulent motions at moisture convergences characterized as substantial moisture variations. COBRA shows a particularly strong sensitivity to cloud tops. Using COBRA to observe, we confirmed that the CBL evolves even over a long and narrow island. On 8 July, a distinct roll cloud formed along the mountain ridge at 1230-1330 JST. The FTM indicated that warmed land can induce roll development in the CBL fully and the roll produces a weak roll cloud in the CBL. The undulated terrain model (CNTL) showed that the terrain reinforces moisture uplifts and produces the distinct roll cloud. Particularly, a merging of the sea-breeze and the roll at the mountain ridge top produces the distinct roll cloud. On 7 July, cellular convection dominated and COBRA observed a cumulus street along the northeasterly oriented COBRA RHI at 1430-1530 JST. At the surface layer, a south- southwesterly wind induces weak rolls across the RHI line. A merging of thermals and the rolls at terrain peaks reinforces upward moisture transfers, thereby initiating cellular convection. The intense moisture uplift at the steep mountain initiates a particularly strong convection penetrating deeply into the free atmosphere. The southwesterly wind above a height of $1 \mathrm{~km}$ advects the cellular convection and generates the cumulus street along the RHI line.

The main difference between observations of 7 and 8 July was the surface wind direction. The wind was south-southwesterly on 7 July across the narrow island around the RHI line, and the wind was southwesterly on 8 July along the island. Though several factors can be considered to initiate the convection. The similar values of CAPE and windshear $\left(1500 \mathrm{~J} \mathrm{~kg}^{-1}\right.$ and $\left.6 \mathrm{~m} \mathrm{~s}^{-1}\right)$ suggest that the presence of similar convective instability at 1300 JST on 8 July and 1500 JST on 7 July. The southwesterly wind traveling over the narrow island allows for full development of rolls in the CBL around the RHI line, and this wind is considered to promote a slightly dry $\mathrm{CBL}$ with rapid for- 
mation in the morning. In contrast, the southsouthwesterly wind induces the weak rolls around the RHI line because of the short land distance; therefore, the roll convection is not dominant. This sea wind creates a moist CBL with slower formation until the late afternoon. Figure 22 shows the relationship between the wind direction and $q_{v}$ at heights of $300 \mathrm{~m}$ and $500 \mathrm{~m}$ obtained from the soundings for July 1 to July 10. The figure shows large (small) $q_{v}$ in southerly (westerly) winds, and this provides evidence of the moist (slightly dry) CBL formation around the RHI line due to the southerly (westerly) winds. Even a small difference in wind direction leads to different CBL structures. This is considered to be a feature of the long and narrow island topography of Okinawa Island.

Our results are based on only two cases, evaluated in rather stable atmospheric conditions. To better clarify the relationship between CBL structures and winds in the surface layer, more studies under various conditions should be conducted.

\section{Acknowledgements}

We wish to express our thanks to all members who conducted the observation on Okinawa Island. We would like to express our appreciation to Prof. Tsuboki, Nagoya University for providing the Cloud Resolving Storm Simulator (CReSS). We would also like to thank two anonymous reviewers for their many constructive comments. This work was supported by the Core Research for Evolutional Science and Technology of the Japan Science and Technology Agency.

\section{Appendix}

\section{Reflectivity of Bragg scattering}

The radar reflectivity factor of Bragg scattering $Z_{b}(\mathrm{dBZ})$ is approximated with the radar wavelength $\lambda(\mathrm{cm})$, the polarizability factor $|\kappa|$ and the refractivity structure parameter $C_{n}^{2}\left(m^{-2 / 3}\right)$ as follows (Knight and Miller 1998):

$$
Z_{b}=\frac{0.38 \lambda^{11 / 3} C_{n}^{2}}{\pi^{5}|\kappa|^{2}},
$$

where $|\kappa|^{2}$ for water is 0.91 at $5.3 \mathrm{GHz} . C_{n}^{2}$ is expressed using the outer length scale $L_{0}(\mathrm{~m})$ and the refractivity gradient $M\left(\mathrm{~m}^{-1}\right)$ as follows:

$$
C_{n}^{2}=a^{2} L_{0}^{4 / 3} M^{2}
$$

where $a^{2}$ is constant and often assigned a value of 2.8 (Tatarskii 1961). So far, $L_{0}$ has been estimated at lengths varying between 1 and a few tens of meters. Jackson (2004) approximated $L_{0}$ in the lower troposphere from windshear (equation $10 \mathrm{c}$ in the report), and $L_{0}$ was estimated $8.8-9.3 \mathrm{~m}$ using our sounding results. In this study, we assigned $L_{0}=$ $9 \mathrm{~m}$ and determined $M^{2}$ as follows:

$$
M^{2}=|\partial N / \partial x|^{2}+|\partial N / \partial y|^{2}+|\partial N / \partial z|^{2} .
$$

The refractivity $N$ (dimensionless) can be approximated using the temperature $T(\mathrm{~K})$, the vapor pressure $e$ and total pressure $P(\mathrm{hPa})$ :

$$
N=\frac{77.6}{T}\left(P+4810 \frac{e}{T}\right) .
$$

\section{References}

Adachi, A., T. Kobayashi, and T. Kato, 2004: Dual wind profiler observations of a line-shaped convective system in southern Kyushu, Japan, J. Meteor. Soc. Japan, 82, 725-743.

Bringi, V. N., and V. Chandrasekar, 2001: Polarimetric Doppler Weather Radar: Principals and Applications, Cambridge University Press, 636 pp.

Chow, F. K., A. P. Weigel, R. L. Street, M. W. Rotach, and M. Xue, 2006: High-resolution large-Eddy simulations of flow in a steep alpine valley. Part I: Methodology, verification, and sensitivity experiments, J. Appl. Meteor. Clim., 45, 63-86.

Crum, T. D., R. I. Alberty, and D. W. Burgess, 1993: Recording, archiving, and using WSR-88D data, Bull. Amer. Meteor. Soc., 74, 645-653.

Endo, S., T. Shinoda, H. Tanaka, T. Hiyama, K. Tsuboki, H. Uyeda, and K. Nakamura, 2008: Characteristics of vertical circulation in the convective boundary layer over the Huaihe River Basin in China in the early summer of 2004, J. Appl. Meteor. Clim., 47, 2911-2928.

Fovell, R. G., 2005: Convective initiation ahead of the sea-breeze front, Mon. Wea. Rev., 133, 264-278.

Grimsdell, A. W., and W. M. Angevine, 1998: Convective boundary layer height measurement with wind profilers and comparison to cloud base, J. Ocean. Atmos. Technol., 15, 1331-1338.

Hardy, K. R., and H. Ottersten, 1969: Radar investigations of convective patterns in the clear atmosphere, J. Atmos. Sci., 26, 666-672.

Ito, Y., 1997: Planetary boundary layer over a small island as observed by a Doppler sodar, Boundary Layer Meteor., 85, 379-390.

Jackson, A., 2004: Modified-Dewan optical turbulence parameterizations, Air Force Research Laboratory Technical Report, AFRL-VS-HA-TR-2004-1116, ADA 432901.

Knight, C. A., and L. J. Miller, 1993: First radar echoes from cumulus clouds, Bull. Amer. Meteor. Soc., 74, 179-188. 
Knight, C. A., and L. J. Miller, 1998: Early radar echoes from small, warm cumulus: Bragg and hydrometer scattering, J. Atmos. Sci., 55, 2974-2992.

Kropfli, R., 1983: A review of microwave radar observations in the dry convective planetary boundary layer, Boundary Layer Meteor., 26, 51-67.

Lothon, M., B. Campistron, S. Jacoby-Koaly, B. Bénech, F. Lohou, and F. Girard-Ardhuin, 2002: Comparison of radar reflectivity and vertical velocity observed with a scannable C-band radar and two UHF profilers in the lower troposphere, J. Atmos. Oceanic Technol., 19, 899-910.

Matthews, S., J. M. Hacker, J. Cole, J. Hare, C. N. Long, and R. M. Reynolds, 2007: Modification of the atmospheric boundary layer by a small island: Observations from Nauru, Mon. Wea. Rev., 135, 891-905.

Minda, H., F. A. Furuzawa, S. Satoh, and K. Nakamura, 2008: Bird migration echoes observed by polarimetric radar, IEICE Trans. Commun., E91-B, 2085-2089.

Nakagawa, K., H. Hanado, S. Satoh, T. Iguchi, and S. Fujii, 2001: Development of the Okinawa polarimetric rain radar: COBRA, Fifth International Symposium on Hydrological Applications of Weather Radar-Radar Hydrology, 153-158.

Sullivan, P. P., C. H. Moeng, B. Stevens, D. H. Lenschow, and S. D. Mayor, 1998: Structure of the en- trainment zone capping the convective atmospheric boundary layer, J. Atmos. Sci., 55, 3042-3064.

Tanaka, H., T. Hiyama, K. Yamamoto, H. Fujinami, T. Shinoda, A. Higuchi, S. Endo, S. Ikeda, W. Li, and K. Nakamura, 2007: Surface flux and atmospheric boundary layer observations from the LAPS project over the middle stream of the Huaihe River basin in China, Hydrological Processes, 21, 1997-2008.

Tatarskii, V. I., 1961: Wave Propagation in a Turbulent Meduim, McGraw-Hill Book Co., Inc., 285 pp.

Tian, W., D. J. Parker, and C. A. D. Kilburn, 2003: Observations and numerical simulation of atmospheric cellular convective over mesoscale topography, Mon. Wea. Rev., 131, 222-235.

Tsuboki, K., and A. Sakakibara, 2001: CReSS User's Guide (in Japanee), Nagoya University, $210 \mathrm{pp}$.

Zeng, J., Y. Fujinuma, H. Mukai, and M. Katsumoto, 2003: Using GPV meteorological data in atmospheric monitoring, National Institute for Environmental Studies (Japan) CGER-REPORT, CGERM014-2003, 75-93.

Zhong, S. Y., and J. Fast, 2003: An evaluation of the MM5, RAMS, and Meso-Eta models at subkilometer resolution using VTMX field campaign data in the Salt Lake Valley, Mon. Wea. Rev., 131, $1301-1322$. 